\title{
Multi-scale meteorological conceptual analysis of observed active fire hotspot activity and smoke optical depth in the Maritime Continent
}

\author{
J. S. Reid ${ }^{1}$, P. Xian ${ }^{2}$, E. J. Hyer ${ }^{1}$, M. K. Flatau ${ }^{1}$, E. M. Ramirez ${ }^{3,}{ }^{*}$, F. J. Turk ${ }^{4}$, C. R. Sampson ${ }^{1}$, C. Zhang ${ }^{5}$, \\ E. M. Fukada ${ }^{6}$, and E. D. Maloney ${ }^{7}$ \\ ${ }^{1}$ Marine Meteorology Division, Naval Research Laboratory, Monterey CA, USA \\ ${ }^{2}$ ASEE Fellow, Naval Research Laboratory, Monterey CA, USA \\ ${ }^{3}$ Dept. of Atmospheric Science, University of Utah, Salt Lake City, UH, USA \\ ${ }^{4}$ Jet Propulsion laboratory, Pasadena, CA, USA \\ ${ }^{5}$ Rosenstiel School of Marine and Atmospheric Science, University of Miami, Miami, FL, USA \\ ${ }^{6}$ Joint Typhoon Warning Center, Pearl Harbor, HI, USA \\ ${ }^{7}$ Dept. of Atmospheric Science, Colorado State University, Ft. Collins, CO, USA \\ *now at: SSAI, Camp Springs, MD, USA
}

Correspondence to: J. S. Reid (jeffrey.reid@nrlmry.navy.mil)

Received: 10 June 2011 - Published in Atmos. Chem. Phys. Discuss.: 27 July 2011

Revised: 9 January 2012 - Accepted: 22 January 2012 - Published: 27 February 2012

\begin{abstract}
Much research and speculation exists about the meteorological and climatological impacts of biomass burning in the Maritime Continent (MC) of Indonesia and Malaysia, particularly during El Nino events. However, the MC hosts some of the world's most complicated meteorology, and we wish to understand how tropical phenomena at a range of scales influence observed burning activity. Using Moderate Resolution Imaging Spectroradiometer (MODIS) derived active fire hotspot patterns coupled with aerosol data assimilation products, satellite based precipitation, and meteorological indices, the meteorological context of observed fire prevalence and smoke optical depth in the MC are examined. Relationships of burning and smoke transport to such meteorological and climatic factors as the interannual El Nino-Southern Oscillation (ENSO), El Nino Modoki, Indian Ocean Dipole (IOD), the seasonal migration of the Intertropical Convergence Zone, the 30-90 day Madden Julian Oscillation (MJO), tropical waves, tropical cyclone activity, and diurnal convection were investigated. A conceptual model of how all of the differing meteorological scales affect fire activity is presented. Each island and its internal geography have different sensitivities to these factors which are likely relatable to precipitation patterns and land use practices. At
\end{abstract}

the broadest scales as previously reported, we corroborate ENSO is indeed the largest factor. However, burning is also enhanced by periods of El Nino Modoki. Conversely, IOD influences are unclear. While interannual phenomena correlate to total seasonal burning, the MJO largely controls when visible burning occurs. High frequency phenomena which are poorly constrained in models such as diurnal convection and tropical cyclone activity also have an impact which cannot be ignored. Finally, we emphasize that these phenomena not only influence burning, but also the observability of burning, further complicating our ability to assign reasonable emissions.

\section{Introduction}

Land management practices in Southeast Asia's Maritime Continent (MC) such as on Borneo, Java, Malay Peninsula, New Guinea, Sulawesi, Sumatra, and Timor include biomass burning to aid in primary forest conversion to agriculture, to maintain oil palm plantations, and to clear agricultural residues such as rice stubble. In particular, the rapid and often illegal expansion of oil palm plantation lands has been 
viewed as the dominant driver of burned area (Stolle and Lambin, 2003; Vayda, 2006; Hansen et al., 2009; Miettinen et al, 2011). Often in drought years, these fires further burn into peatlands with high fractional smoldering emissions and little means of control. The resultant emissions in the MC are globally significant in extreme episodes and regionally significant in nearly all years (e.g., van der Werf et al., 2004, 2008; Giglio et al., 2006; Field et al., 2009; Reid et al., 2009). Ultimately, conversion and degradation of peatlands are of great concern to regional carbon budgets (Miettinen and Liew 2010a; Hergaualch and Verchot, 2011; Page et al., 2011).

Studies of variation in MC smoke have largely focused on El Nino Southern Oscillation (ENSO) which is well known to dominate the interannual fire signal, punctuated by the 1997 event (e.g., Nichol, 1998; Siegert et al., 2001; Parameswaran et al., 2004; Langmann and Heil, 2004; Fuller et al., 2006; Field and Shen, 2008; van der Werf et al., 2004, 2008; Graf et al., 2009; Langner and Siegert, 2009; Field et al., 2009; van der Kaars et al., 2010). Warm phase ENSO conditions (i.e., El Nino) lead to negative summertime precipitation anomalies in the MC. With decreases in precipitation fire activity increases dramatically. Peatlands drained of moisture are, at some critical tipping point, ignited by adjacent agricultural maintenance or forest conversion fires. These fires can last for days or perhaps weeks (Miettinen et al., 2010). Thus warm ENSO years lead to extensive burning which dominates any basic regional statistical analysis of fire counts, the carbon budget or aerosol optical depth (see all references above). It then follows that severe fire outbreaks can induce large perturbations in the regional solar radiation budget with daily averaged top of atmosphere and surface forcing up to -50 and $-200 \mathrm{~W} \mathrm{~m}^{2}$, respectively for the massive 2007 event (Davidson et al., 2004; Rajeev et al., 2008), and reductions in surface photosynthetically active radiation (PAR) by up to $75 \%$ (Kobayashi et al., 2004). Atmospheric heating rates for smoke layers during the 2006 event were reported to be on the order of $1 \mathrm{~K} \mathrm{day}^{-1}$ (Thampi, et al., 2009). With respect to cloud development, there have been suggestions of increased storm severity (Hamid et al., 2001) and decreased ice crystal size and perhaps precipitation (Jiang et al., 2008). Smoke impacts have even been observed in the coral record (Risk et al., 2003). In many of the studies cited above, there have been suggestions of fire feedbacks with the meteorological environment (e.g., Field et al., 2009; Graf et al., 2009; Tosca et al., 2010).

The focus on the most extreme events in previous literature likely oversimplifies and distorts biomass burning's true role in the physical and social environment of the MC. It is well known that through the Twomey effect (i.e., first indirect effect), clouds have different saturation effects with regards to smoke CCN environments depending on size, super saturation, etc. (e.g., Reid et al., 1999; Feingold et al., 2001; Andreae et al., 2004; Lohomann and Feichter, 2005). Regional atmospheric radiation feedbacks between aerosol absorption and shallow cloud cover are also complicated in the tropical atmosphere (e.g., Mcfarquhar and Wang, 2006). Both numerical weather prediction (NWP) and climate models have difficulty representing the complex meteorological features of the MC including ENSO (e.g., Latif, et al., 1998, Achutarao and Sperber 2006, Aldrian et al 2007). Because the ENSO signal is so dominant (punctuated with the massive event of 1997-1998) as is seasonal fire behavior, unsupervised statistical analyses (e.g., factor analyses, cluster analyses, machine learning/neuralnet etc.) may account for some variance, but only at the expense of more typical seasons. Organizing burning cause and effect relative to these phenomena ignores details which may be important, especially in more climate-normal years. Understanding the relationships between fire activity, timing, emissions, and the atmospheric state in both active and mild fire years is required.

Fire activity in the MC is overwhelmingly anthropogenic, and thus is expected to be largely dictated by societal pressure for clearing and maintenance constrained by meteorological parameters, in particular precipitation. Nominally there are five scales of concern over the MC: (1) Interannual features such as ENSO (Rasmussen and Wallace, 1983; Mcbride et al. 2003), ENSO Modoki (Ashok et al., 2007) and the Indian Ocean Dipole (IOD, Saji et al., 1999; Saji and Yamagata, 2003; Schott et al., 2009); (2) Seasonal migration of the Intertropical Convergence Zone (ITCZ) and its associated summer and winter monsoons (Chang et al., 2005; Wang et al., 2009); (3) Intraseasonal synoptic phenomenon such as the 30-90 day oscillation or the Madden Julian Oscillation (MJO) (Madden and Julian, 1971; Zhang, 2005; Wu et al., 2009) and the west Sumatran low (Wu et al., 2009); (4) Wave and mesoscale features feature such as fronts and tropical cyclones (Goh and Chan, 2010) in northern SEA, and equatorial waves, such as the Kelvin, Rossby, and Easterly waves in the MC (Kiladas et al., 2009), or tropical cyclones; and (5) Regional convection from localized weather phenomena, such as fair weather cumulous, orographically modified flows, thunderstorms, sea breeze circulation, etc. (Yang and Smith 2006; Mahmud, 2009a, b; Li et al. 2010; Sow et al., 2011). However, it must be recognized that the meteorology of the MC has interconnecting influences among all of the above meteorological scales. Adding perhaps the largest and most complex layer is the human element (Vayda, 2006) and how anthropogenic activities covary with the above meteorology.

Compounding the difficulties of fire studies of the MC is that the above meteorological scales impact not only fire activity in the region, but also the observability of fire for both active fire hotspot and burn scar methods. Conventional ground-based measurements are sparse, and satellite observations must cope with ubiquitous cloud cover. Even during "good weather" cirrus clouds are frequent and interfere with the measurement of active fires and the resulting gas and particle emissions alike. Microwave and radar precipitation products are hindered by the heterogeneous surface 
of shallow seas and small islands. Agricultural stack and burn methods common in plantations and deforestation create other observability issues, contributing significantly to regional atmospheric pollution while frequently escaping detection by satellite fire algorithms. These observational limitations of the MC can lead to a host of instrument, algorithmic and contextual biases (Schroeder et al. 2008a; Zhang and Reid, 2009; Hyer et al., 2011, 2012). While cloud cover is always high in the MC, it is nonetheless variable, and this variability is intertwined with the meteorological patterns and surface processes that interact with biomass burning. The decadal variability of physical (e.g., ENSO) and anthropogenic (e.g., forest conversion) characteristics coupled with orbit shifts also leads to consistency problems from monitoring from one satellite product to the next (Giglio et al., 2006). At the broadest scales, fire activity will be greater in less cloudy conditions (It is a truism for anyone in the fire community clear skies mean higher surface solar fluxes/temperatures and hence enhanced burning, e.g., Johnson and Miyanishi, 2001. Further, clear skies implies no rain). Models have simulation problems, which have difficulty with the fine orographic scale of the region (Neale and Slingo, 2003) or have inconsistent assimilation data over decadal scales. Conclusions for fire-meteorology studies must consider contextual bias, statistical confounding, tautology, and inverted causality.

The 7 Southeast Asian Studies (7SEAS) project was formed to directly address the issues surrounding aerosolmeteorology interaction and observability throughout Southeast Asia. 7SEAS will participate with other research efforts to perform the Southeast Asian Composition, Clouds and Climate Coupling Regional Study (SEAC4RS). The early 7SEAS and SEAC4RS research leading to this particular manuscript relates to questions on the basic phenomenology of fire outbreaks in the MC. These included: (1) What are the island specific sensitivities to interannual, seasonal, and intraseasonal scale weather phenomena? (2) How do meteorological conditions impact the onset and cessation of individual fire outbreaks? (3) What is the nature of mid-fire season precipitation events? (4) What is the nature of fire during the wet season? In this study we perform a simple analysis of Moderate Resolution Imaging Spectroradiometer (MODIS) active fire hotspot prevalence and satellite precipitation estimates on the islands of the MC. Using an aerosol transport model with data assimilation, we then examine basic smoke lifecycle properties. From this we perform a consistent analysis throughout the MC to help unify many specific and more focused research efforts found in the literature. Even so, this study cannot be construed as complete. As will be shown, the complexity of the meteorological system is staggering with numerous outstanding questions on fundamental tropical weather, land surface processes, remote sensing, and fire science topics.

In this study we begin with an overview of fire behavior in Southeast Asia. From this we work downward in scale from the largest interannual variability to seasonal, synoptic/mesoscale, and local/diurnal scale meteorology. Because of the convoluted nature of meteorology in the region, each topic is predicated on the one prior to it. In the discussion, we provide some unifying threads in the meteorology-fire relationship how they relate to predictability. Finally, we present several hypotheses regarding the nature of burning activity and fire prediction in the region.

\section{Datasets}

The term "Maritime Continent" (henceforth MC) varies from study to study and is used primarily to describe the portion of Southeast Asia comprising the Malay Peninsula through the island chains of Malaysia, Indonesia, Timor Leste, and Papua New Guinea. Longitudinal and latitudinal descriptions vary, but here we investigate the region covering $10^{\circ} \mathrm{S}$ to $10^{\circ} \mathrm{N}$ latitude $90-150^{\circ} \mathrm{W}$ longitude, this includes the above countries as well as the island of Mindanao, Philippines. While we utilize data going back to 2000, focus is on the 2003-2009 period because we have complete coverage of MODIS instruments, several satellite based products, and aerosol model reanalyses.

\subsection{Fire data}

In this study we focus on fire prevalence and AOD coverage rather than the much more complicated smoke flux. Estimation of smoke flux from fire products introduces large uncertainties from variations in fire behavior as well as basic observational challenges such as attribution of fuels (Reid et al., 2009; Hyer and Reid, 2009). There are many reasons that current state-of-the-science fire products can be considered only semi-quantitative in the MC. Cloud cover blocks the heat signature of fires, and even during "good weather" cloud cover requires count correction (Giglio et al., 2006; Schroeder et al., 2008a). Such cloud contamination not only impacts active fire hotspot data, but can impact differential methods to identify burn scars, particularly during wetter periods when repeated clear views of a target are difficult to obtain. Under perfect observing conditions, MODIS fire detection will exhibit variability caused by variation in pixel geometry across the scan as well as gaps between orbits near the equator (Giglio et al., 2006). Lastly, there is the problem that many fires occurring in this region are too small to be detected by either fire hot spot or burn scar satellite products (e.g. Miettinen and Liew, 2009). This problem can be exacerbated by smaller fires, fires that burn at lower temperatures (common in peat burning), as well as fires burning understory vegetation beneath closed canopies. The best results will likely be obtained by a multi-sensor, multi-algorithm approach, but such products are under construction.

While satellite fire counts are semi-quantitative at best in the MC, burn scar algorithms will also have large 
uncertainties and some systematic biases in this region, that are currently less well-characterized relative to active fire data (e.g. Miettinen et al., 2007; L. Giglio personal communication, 2011). However, very recently attempts have been made to estimate emissions from such data for the first half of the MODIS era (e.g., Chang and Song, 2010). For this study, we restrict ourselves to analyses that require mainly interannually consistent fire characterization. To this end, we used the nearly ten year 2000-2009 active fire hotspot data set of MODIS Terra $(\sim 10: 30$ LST) and Aqua $(\sim 13: 30$ LST), with a particular focus of 2003-2009 where a complete record exists (Justice et al. 2002; Giglio et al. 2003). The 13:30 LST Aqua overpass is beneficial as peak burning in the region coincides with this orbit (Giglio, 2007). This said, we recognize that in some regions, such as the Malaysian provinces on Borneo, fire activity peaks in the very late afternoon (Hyer et al., 2012). For specific purposes in this paper, we use a 9-day boxcar filter (i.e., 9 day center day average) on regional fire counts to generate our fire time series. This is short enough for monitoring fire events and trends yet still long enough to average out orbit track issues.

\subsection{Precipitation data}

Like fire, precipitation monitoring in the $\mathrm{MC}$ is challenging. Of the four primary sources (rain gauge networks, groundbased radar, satellite methods-including radar and passive microwave and NWP model analyses), only the last two are viable sources region wide, including over ocean. NWP precipitation has been shown to have qualitative skill at capturing tropical rainfall amounts at monthly and seasonal scales, but has difficulty resolving the timing and magnitude of daily or even weekly convection in the tropics ( Adler et al., 2001; Dai, 2006, Sun et al., 2007; Ebert et al., 2007).

For this study we predominantly rely on satellite based sub-daily time scale high resolution precipitation products (HRPP), which utilize the fast-refresh (30 min or less) observational capabilities from imagers onboard one or more geostationary Earth orbiting (GEO) platforms. While such observations are largely sensing cloud top properties and are thereby indirectly linked to the underlying precipitation structure, they have attained a high degree of utilization owing to the efforts of the Global Precipitation Climatology Program (GPCP, available back to 1979) ( Huffman et al., 2009) and the joint NASA/JAXA Tropical Rainfall Measuring Mission (TRMM) ( Huffman et al., 2007). Our analyses here are based on the high resolution Climate Prediction Center (CPC) MORPHing technique (CMORPH, Joyce et al., 2004). Available in a consistent form since 2002, the principles behind CMORPH are fundamentally different than those for GPCP. Unlike techniques which use IR data to quantitatively assign precipitation, CMORPH uses the fastrefresh geostationary imagery in a qualitative fashion, to transport or "morph" the instantaneous LEO orbiting based satellite precipitation products in time (e.g., Special Sensor
Microwave Imager (SSMI) and Sounder (SSMIS), Advanced Microwave Sounding Unit (AMSU), Microwave Humidity Sounder (MHS), and the Advanced Microwave Scanning Radiometer (AMSR-E)). Here, we use native CMORPH data at a three-hour and one-quarter degree (latitude and longitude, gridded) resolution for our analysis. While no fully comprehensive satellite validation study has been conducted in the MC, CMORPH in general appears to have the best representation of temporal and spatial patterns of tropical precipitation and complex terrain (Janowiak et al., 2005; Dinku et al., 2008; Sapiano and Arkin, 2009; Shen et al., 2010). Even so, systematic biases exist in the individual satellite products used in the morphing algorithm (Sapiano and Arkin, 2009; Wolff and Fisher, 2009). Indeed, in our limited comparison of CMORPH to the CPC Gauge analysis, CMORPH consistently underestimated precipitation by $\sim 30 \%$ on the monthly timescale over land, opposite in sign to the global bias reported by Sapiano and Arkin (2009). In our analysis, however, we are more interested in spatial and temporal variability than absolute magnitudes and deem CMORPH the most appropriate product.

In addition to CMORPH, we use for comparison purposes the half-degree global Unified Gauge Analysis (Chen et al., 2008) segmented over the MC. Lastly, we use TRMM satellite products to identify tropical waves through spectral filtering.

\subsection{Meteorological indices}

Fire and precipitation data were interpreted in the context of several meteorological indices. As described in the results section migration of the ITCZ was identified by the median latitude of CMORPH precipitation and low level winds in the South China Sea (SCS). For the ENSO, IOD and MJO we use the well defined and accepted multivariate indices of Wolter and Timlin, (1998), Saji et al. (1999), and Wheeler and Hendon, (2004), respectively. In addition to these indices, we applied others which are more directly applicable to precipitation. First, in order to separate out influence of the MJO and Kelvin waves on precipitation, a spectral analysis of precipitation fields was conducted, following the procedure used by Wheeler and Kiladis (1999). Using a Fast Fourier Transform on TRMM precipitation data, MJO precipitation events were identified at 105 degrees longitude (between Sumatra and Borneo) by filtering for eastward propagating events with 40-60 days period and zonal wavelength 1 through 8 . Similarly, Kelvin waves were extracted for eastward propagating precipitation events with phase speeds from $12 \mathrm{~m} \mathrm{~s}^{-1}$ to $20 \mathrm{~m} \mathrm{~s}^{-1}$ and zonal wavelengths from 1 to 14 .

\subsection{Model data}

Meteorological model data for individual events and anomalies are used throughout the study. For the core period of study, we rely on a one degree interpolation of the Navy 
Global Atmospheric Prediction System (NOGAPS; Hogan and Rosmond, 1991). We compared NOGAPS fields to the NCAR reanalysis fields (Kalnay et al., 1996) for the individual events discussed in this paper and found no substitutive difference in winds. NOGAPS data is subsequently used in the offline Navy Aerosol Analysis and Prediction System (NAAPS), the Navy's operational aerosol model. In a 10 year reanalysis run, NAAPS uses the Fire Locating and Modeling of Burning Emissions (FLAMBE) system (Reid et al., 2009) and combined with MODIS aerosol optical depth assimilation (Zhang et al., 2008). Wet deposition through convective precipitation is constrained with the CMORPH precipitation product via the method of Xian et al. (2009). This model has been successfully employed for MC smoke in the past (Reid et al., 2009; Hyer and Chew, 2010).

\section{Results: overall bulk seasonal fire phenomenon of the Maritime Continent}

In this first results section we give an overview of the seasonal fire behavior from which we anchor our subsequent sections on meteorological context. The nature of biomass burning in Southeast Asia can be observed in Fig. 1a which shows the 9-day boxcar average MODIS fire seasonal counts for Indochina (Cambodia, Laos, Myanmar, Thailand, Vietnam) (scaled by 1/5) and the Maritime Continent (Indonesia, Malaysia, Timor-Leste, Papua New Guinea, and MindanaoPhilippines) for 2003-2009. Error bars represent interannual standard deviations for each day. Also shown is the CMORPH derived median latitude of precipitation for the same period for the longitude range of $90-150^{\circ} \mathrm{E}$. As expected, fire activity is opposite the seasonal migration of the ITCZ. At the ITCZ's furthest southern extent (i.e., "Winter Monsoon"), fire activity in Indochina peaks. Conversely, at the most northward extent of the ITCZ (i.e., "Summer Monsoon"), fire activity in the MC peaks. There is, however, a $\sim 1$ month lag between peaks in fire versus ITCZ migration perhaps as a "fuel drying period." The meteorological patterns associated with the seasonal extremes are represented in CMORPH precipitation and NOGAPS $850 \mathrm{hPa}$ winds in Fig. $1 \mathrm{~b}$ and $\mathrm{c}$ for the maximum southern and northern extent of the ITCZ, respectively. In the following subsections we elaborate further.

\subsection{Seasonal monsoonal cycle}

A full description of the meteorology of the MC monsoonal periods can be found in Chang et al. (2005), Moron et al, (2009), Wang et al. (2009), and most recently, the book edited by Chang et al., (2011). However, in regards to impact on burning activity there are some basic precipitation features worth noting. Starting east and working westward, we have the Northern Hemisphere ITCZ and a South Pacific convergence zone associated with two rain bands embedded
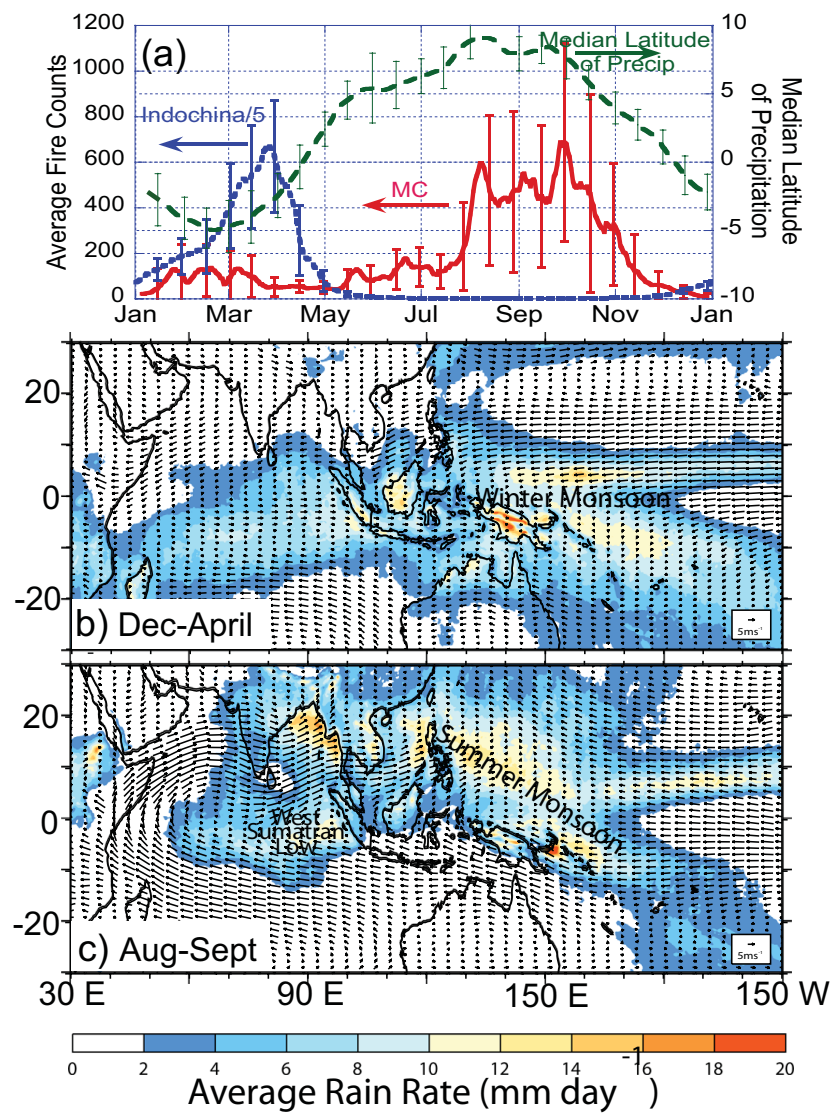

Fig. 1. (a) 2003-2009 average seasonal cycle of MODIS active fire hotspot prevalence (counts day ${ }^{-1}$, with 9-day boxcar smoothing applied) in Indochina (divided by 5) and the Maritime Continent over plotted with the CMORPH derived median latitude for precipitation rate. Bars represent the interannual standard deviation for each period. (b) and (c) 2003-2009 average CMOPRH precipitation rate $\left(\mathrm{mm} \mathrm{day}^{-1}\right)$ overlaid by NOGAPS average $850 \mathrm{hPa}$ winds for August-September and December-April, respectively.

in trade winds in the central Pacific. The monsoon trough pivots from a Southern Hemisphere zonal feature in the boreal winter monsoon to a boreal summertime diagonal feature that extends into the Northern South China Sea where it is anchored over land in Indochina and into the Indian monsoon. A portion of this summer monsoonal trough precipitation is not simple ITCZ convection, but also a result of wave formation and tropical cyclone genesis within the trough. Within Indochina, the CMORPH precipitation fields clearly illustrate the relative boreal spring "Dry" and summer "Wet" seasons. However, within the MC, the difference between precipitation in the summer and winter monsoonal periods is about $50 \%$, and could be better characterized as "Wet" and "Wetter." This asymmetry in monsoonal precipitation across the equator is described in Chang et al. (2005). A "Total dry line" is roughly at $\sim 5^{\circ} \mathrm{S}$ latitude and encompasses Java, Bali, southern Sulawesi and Timor. North of this line, scattered 
precipitation is normal throughout the "dry season". Finally, a persistent rainfall maximum occurs over the Indian Ocean west of Sumatra, with winter monsoon periods being dominated by the ITCZ, and in summer perhaps by the western Sumatran Low (Wu et al., 2009). Monsoonal precipitation is also present as oceanic air begins convergence as it makes landfall in the northern Bay of Bengal and Philippines.

Along with the monsoonal nature in precipitation comes a significant change in the wind field. The shift from winter to summer monsoon corresponds to a surface flow reversal from Northeast to Southwesterly winds in the SCS, and from very light easterly to intense westerlies on the northern Indian Ocean and the Bay of Bengal. In the sea surrounded by Borneo and Sumatra winds do not have a strong prevailing direction, although the region is generally embedded in large-scale positive wind curl in boreal winter and negative curl in boreal summer that connects to flow in the SCS.

\subsection{Bulk seasonal fire behavior}

Throughout the MC there is spatial heterogeneity in fire detection. Within Fig. 1a it is clear that there remains some offseason burning in the MC. Figure 2 presents 2003-2009 average total MODIS Terra and Aqua fire prevalence (detections per year, per $1000 \mathrm{~km}^{2}$ ) for (a) "summer" and (b) "winter" monsoonal periods. To ensure no boreal summer monsoon dry season contamination in the off winter monsoon season fire map we generously bounded the dry season from June through November, roughly corresponding to times with the passing of the median precipitation latitude of $5^{\circ} \mathrm{N}$. Region labels and statistics are provided in Table 1 and were selected on both fire geography and political bounds. Included are the average annual prevalence, and the percentage of fires relative to the entire MC domain. Also shown is the fraction of fires contained within the June-November total fire season, the mean and modal month, as well as the typical season start and end date as defined by $\pm 1 \sigma$ of fires detected derived directly from a cumulative distribution function (i.e., start is at $16 \%$ of fires observed, end at a total of $84 \%$ observed). Lastly, relative nighttime percentage and observed ratios for the morning $(\sim 10: 30 \mathrm{LST})$ versus afternoon $(\sim 13: 30 \mathrm{LST})$ MODIS data are provided.

Clearly during the summer monsoonal period fire is widespread throughout the MC. As described in many previous papers (e.g., van der Werf et al. 2004, 2008; Giglio et al., 2006; Field and Shen, 2008; Reid et al., 2009) the regions of most significant fire prevalence include southern Kalimantan, Borneo, Indonesia (\#9), and fire hotspots in central and southern Sumatra, Indonesia (\#4 and 5, respectively). These three regions account for $\sim 50 \%$ of all observed fire counts in the MC and correspond nearly identically to the fire EOF analysis presented in Field and Shen (2008) as well as maps of regional peat swamp (Tansey et al., 2008; Miettinen et al., 2010b). Indeed, Tosca et al. (2011), reported that $75 \%$ of

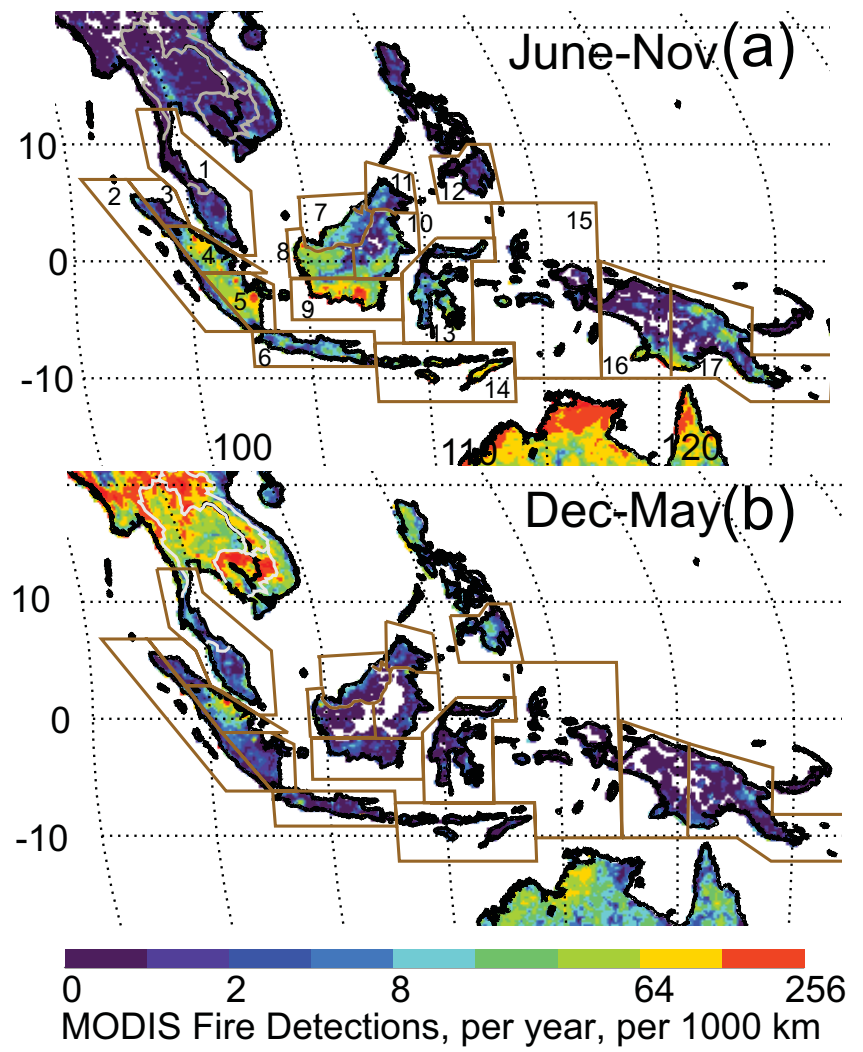

Fig. 2. (a) Average regional MODIS active fire hotspot prevalence for the June through November dry season. (b) Same as (a) for the December-May wet season. Included in (b) are labels for regional analyses and discussions: (1) Malaysian Malay Peninsula; (2) Western Sumatra, Indonesia; (3) Northern Sumatra, Indonesia; (4) Central Sumatra, Indonesia; (5) Southern Sumatra, Indonesia; (6) Java and Bali, Indonesia; (7) Sarawak, Western Borneo, Malaysia and Brunei; (8) Western Kalimantan, Indonesia; (9) Southern Kalimantan, Indonesia; (10) Eastern Kalimantan, Indonesia; (11) Northern Borneo, Sabah; (12) Mindanao, Philippines (13) Sulawesi, Indonesia; (14) Timor, Leste, and Southern Islands, Indonesia; (15) Maluku, Indonesia; (16) Papua, Indonesia; (17) Papua New Guinea.

observed plumes in their study were associated with peatland areas.

In all, the islands of Borneo and Sumatra account for $70 \%$ of all observed fire detections in the MC, $94 \%$ of which are in Indonesia. These high fire prevalence regions are known for deforestation, palm plantation and lowland forest peatlands (e.g., Miettinen et al., 2008). In burning per unit area (Fig. 2), there are other regions that, during the MC summer monsoonal period, also have moderate burning prevalence. The island of Sulawesi (\#13) shows fairly high burning activity and in some cases localized fire density that largely parallels Borneo, but with roughly an order of magnitude less in total observed fire count. The southern islands east of Java (\#14), most notably Timor, show the highest fire prevalence outside of Borneo and Sumatra. Similarly, New Guinea has 
Table 1. Average burning statistics from Terra and Aqua for regional domains in the Maritime Continent as defined in Fig. 2.

\begin{tabular}{|c|c|c|c|c|c|c|c|c|c|c|}
\hline Key & Location & $\begin{array}{l}\text { Average } \\
\text { Prevalence } \\
* \mathrm{yr}^{-1}\end{array}$ & $\begin{array}{l}\% \\
\text { Fires in } \mathrm{MC}\end{array}$ & $\begin{array}{l}\% \text { Fires } \\
\text { Jul-Nov }\end{array}$ & $\begin{array}{l}\text { Season } \\
\text { Start }\end{array}$ & Mean & $\begin{array}{l}\text { Season } \\
\text { End }\end{array}$ & $\begin{array}{l}\text { Mode } \\
\text { Month }\end{array}$ & $\%$ Night & $\begin{array}{l}\text { Aqua PM/ } \\
\text { Terra AM }\end{array}$ \\
\hline \multirow[t]{2}{*}{ * } & Brunei & 55 & $<0.1 \%$ & $40 \%$ & $15 \mathrm{Mar}$ & 30 May & 30 Aug & Aug & $7 \%$ & 3.0 \\
\hline & Indonesia & & & & & & & & & \\
\hline 6 & Java and Bali & 2120 & $3 \%$ & $70 \%$ & 30 May & 14 Aug & $15 \mathrm{Oct}$ & Sept & $19 \%$ & 1.0 \\
\hline 10 & Kalimantan, Eastern & 3085 & $4 \%$ & $86 \%$ & $30 \mathrm{Jul}$ & $7 \mathrm{Sep}$ & 7 Oct & Sep & $23 \%$ & 6.7 \\
\hline 9 & Kalimantan, Southern & 13892 & $20 \%$ & $96 \%$ & 15 Aug & $20 \mathrm{Sep}$ & $7 \mathrm{Oct}$ & Sep & $21 \%$ & 3.1 \\
\hline 8 & Kalimantan, Western & 5370 & $8 \%$ & $90 \%$ & $20 \mathrm{Jul}$ & 20 Aug & 20 Sep & Sep & $5 \%$ & 20.0 \\
\hline 15 & Maluku Islands & 890 & $1 \%$ & $83 \%$ & 7 Aug & 7 Oct & $15 \mathrm{Nov}$ & Oct & $3 \%$ & 2.0 \\
\hline 16 & Papua & 2460 & $3 \%$ & $91 \%$ & $30 \mathrm{Aug}$ & 7 Oct & 15 Nov & Oct & $2 \%$ & 3.1 \\
\hline 14 & S. Islands \& Timor & 3985 & $6 \%$ & $91 \%$ & $30 \mathrm{Jul}$ & 20 Sep & 31 Oct & Oct & $1 \%$ & 2.0 \\
\hline 4 & Sumatra, Central & 10990 & $17 \%$ & $39 \%$ & 14 Feb & 7 Jun & 7 Aug & Aug & $24 \%$ & 2.0 \\
\hline 3 & Sumatra, Northern & 210 & $<0.5 \%$ & $43 \%$ & $7 \mathrm{Mar}$ & $20 \mathrm{Jun}$ & $20 \mathrm{Aug}$ & Aug & $3 \%$ & 3.3 \\
\hline 5 & Sumatra, Southern & 9400 & $14 \%$ & $92 \%$ & $30 \mathrm{Jul}$ & 7 Sep & 20 Oct & Aug & $19 \%$ & 4.3 \\
\hline 2 & Sumatra, Westward & 1760 & $3 \%$ & $42 \%$ & $15 \mathrm{Mar}$ & 15 Jun & 20 Sep & Aug & $8 \%$ & 3.3 \\
\hline \multirow[t]{2}{*}{13} & Sulawesi & 3430 & $5 \%$ & $83 \%$ & $30 \mathrm{Jul}$ & 7 Oct & 7 Nov & Oct & $9 \%$ & 2.5 \\
\hline & Malaysia & & & & & & & & & \\
\hline 1 & Malay Peninsula & 1550 & $2 \%$ & $26 \%$ & $7 \mathrm{Feb}$ & $14 \mathrm{Apr}$ & $30 \mathrm{Aug}$ & Feb & $20 \%$ & 1.0 \\
\hline 11 & Sabah, Borneo & 640 & $1 \%$ & $40 \%$ & 7 Mar & 30 May & 20 Sep & Aug & $15 \%$ & 2.7 \\
\hline 7 & Sarawak, Borneo & 1982 & $3 \%$ & $70 \%$ & 7 May & $20 \mathrm{Jul}$ & 14 Sep & Aug & $5 \%$ & 5.6 \\
\hline 17 & Papua New Guinea & 5170 & $7 \%$ & $81 \%$ & 15 Jun & $20 \mathrm{Sep}$ & $7 \mathrm{Nov}$ & Oct & $3 \%$ & 3.7 \\
\hline 12 & Philip.-Mindanao & 870 & $1 \%$ & $7 \%$ & $14 \mathrm{Feb}$ & $20 \mathrm{Mar}$ & $30 \mathrm{Apr}$ & Mar & $0 \%$ & 4.0 \\
\hline$*$ & Timor Leste & 1120 & $2 \%$ & $96 \%$ & $20 \mathrm{Aug}$ & 7 Oct & $20 \mathrm{Oct}$ & Oct & $1 \%$ & 2.1 \\
\hline
\end{tabular}

* Brunei has such low fire prevalence in all other analyses it is included in area 7.

regions of active fires in the southern and eastern portion of the island (\#16 and \#17). Moderate burning can also be found on Java (\#6) and Maluku (\#15). A small fraction Java fire activity may be contaminated with volcanic signal.

There are distinct temporal patterns to the fire season. Based on all fires, the fire season generally runs from July through October, with the bulk of burning occurring in the August and September timeframe. However, each region has a very distinct perturbation on this mean. In general, fire activity start dates and peak burning occur earliest in the western MC and later further east. For example the fire season in Sumatra starts and ends earlier than the rest of the region. Papua, Maluku, and Sulawesi Indonesia as well as Papua New Guinea all burn into November. The largest emitter, Southern Kalimantan, has a distinct mid August to September fire season. Western and Eastern Kalimantan, however, start and have means several weeks earlier. This pattern in fire activity matches well with work that showed an eastward propagating start date for the rainy wintertime monsoon across the MC (Moron et al., 2009). For the Malaysian Borneo provinces of Sarawak and Sabah fire activity is low and noticeably weighted earlier in the season, perhaps due to stricter burning regulation, or also due to the shift in burning activity to later in the afternoon relative to other regions in the MC (Hyer et al., 2012). This is interesting as these provinces have nevertheless seen massive peat swamp deforestation (Miettinen et al., 2011).

Islands have a distinct observed diurnal cycle of burning. Nighttime detections are low, typically less than $10 \%$, although Kalimantan, Java and Central Sumatra have slightly higher fractions. The observed ratio of Terra morning to Aqua afternoon fire counts, however, is more variable. Globally there is a strong observed diurnal cycle of fire hotspots which peaks after noon local solar time (LST) and Aqua counts globally are roughly twice Terra (Csiszar et al., 2005; Reid et al, 2009). However, throughout the MC there appears to be considerable variability in observed diurnal cycles. In Java and the Malay Peninsula, morning and afternoon counts are almost even. In the southern Islands of Indonesia, Timor Leste, and central Sumatra, morning counts are $\sim 1 / 2$ the afternoon, typical of the global average. Other islands and regions show lower morning fire counts with less than a third to a tenth of the afternoon. This is discussed further in Sect. 8.

Fire prevalence is dramatically reduced in the wetter winter monsoonal period, but it is not non-existent with isolated fires being detected all year around. Most notably, central Sumatra shows an area of very intense burning slightly south of a similar hotspot in the summer monsoon which rivals the more typical dry season. The $500 \mathrm{~m}$ Miettinen and Liew (2010b) MODIS derived biome map suggests these fires to 

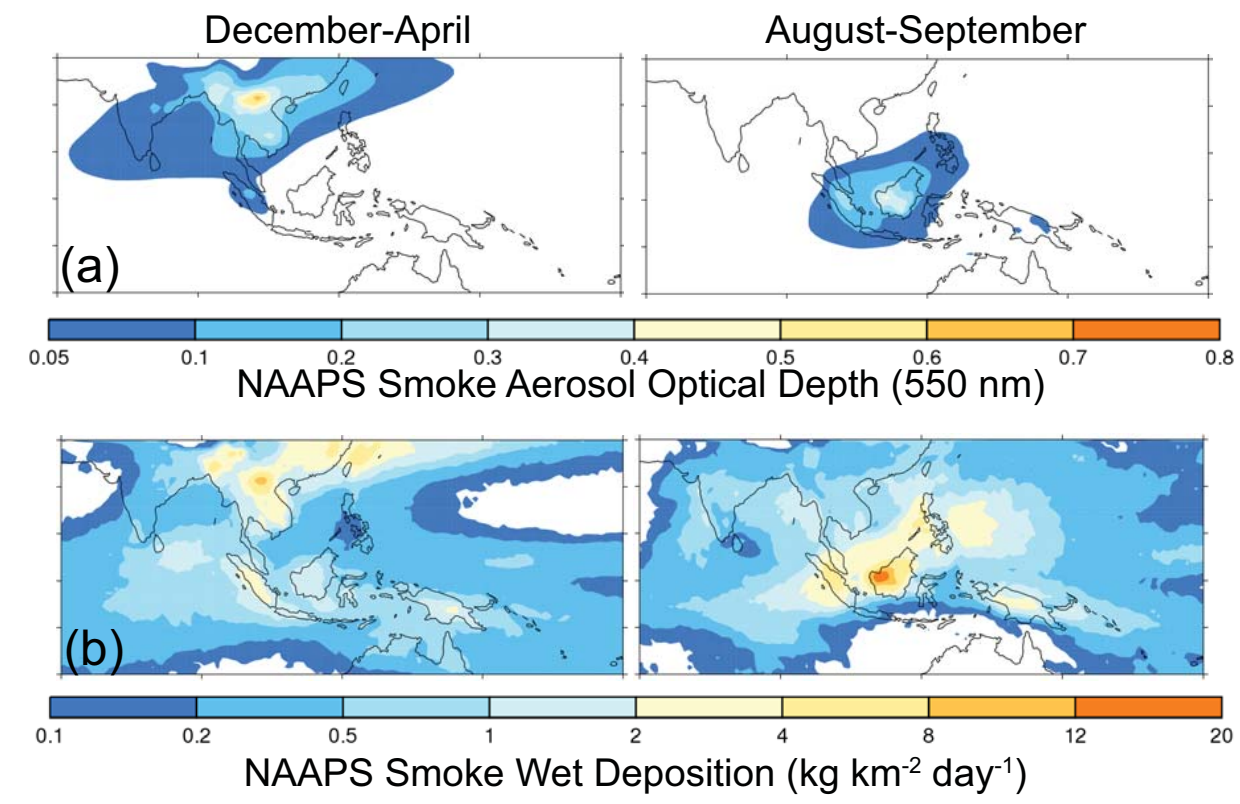

Fig. 3. 2003-2009 NAAPS mean AOD (a) and (b) and wet deposition fields (c) and (d) for the peak boreal winter (December-April) and summer (August-September) burning seasons.

be in a "lowland mosaic", which is land categorized by rural agricultural and plantation. The fire peak seen in Fig. 2b is north of the Riau area of rapid forest conversion for plantation documented by Miettinen and Liew (2005). Indeed, Hansen et al. (2008) reports this as the area of most rapid deforestation in Indonesia. This is not simply due to conversion to palm oil plantation, however, but also in part due to a long standing government program to increase rice cultivation as well. Notable events occur in January and February as well as late September, with distinct modal months of February, June and August. Overall, only $39 \%$ of fires in central Sumatra are associated with the typical burning season, and significant air quality impacts in Singapore have been reported in the heart of the wet season (Balasubramanian et al., 2003). Moderate burning can also be found intermittently in isolated agricultural pockets in Malaysian Sarawak on Borneo, the Malay Peninsula, and New Guinea. Less surprising is burning on Mindanao, Philippines, as it is functionally in the winter monsoon dry region with the rest of Indochina.

Seasonal transport patterns associated with the summer and winter monsoon can be elucidated through Fig. 3 where we present NAAPS model AOD fields and wet deposition fluxes for the time periods corresponding to Fig. $1 \mathrm{~b}$ and $\mathrm{c}$. Recall that these simulations include MODIS hotspot data for the source function, MODIS AOD data assimilation, and wet deposition prescribed by the CMORPH algorithm. The highest AODs during the peak of the Summer Monsoon surround the island of Borneo and extends into the southern SCS. The smoke patterns are relatively diffuse, suggesting that atmospheric disturbances may help to laterally mix smoke away from source regions. Atmospheric synoptic disturbances have been documented to act as an important horizontal diffusive process for atmospheric water vapor in the tropical east Pacific (e.g. Peters et al. 2008), and may play a similar role here. As shown in Fig. 1b, the prevailing SW winds in the SCS, Sulu Sea, and Celebes Sea transport the smoke towards the Philippines. Some smoke also works its way into the Indian Ocean from the light easterlies south of Borneo. While these maps are consistent with global meteorological fields, we must be weary of terrain induced bias. Both Sumatra and Borneo have high volcanic peaks, and there is evidence that suggests that transport may go around these mountainous regions rather than "over" as suggested in the NAAPS model (e.g., Xian et al., 2012; Wang et al., 2012).

Based on wet deposition maps (the dominant removal mechanism for smoke), we can see key regimes of rain-out and by implication perhaps smoke-precipitation interaction. These are spread between areas within and transported away from the source region. The model coupled with satellite based precipitation shows that the majority of smoke interacts with summer time convection over land. Smoke transported into the SCS interacts with sporadic maritime precipitation. However, this transported smoke ultimately is scavenged when it reaches the axis of the summer monsoonal trough. Smoke working its way west of Sumatra is largely scavenged by over land thunderstorms and precipitation associated with the western Sumatra Low. Owing to its CO signal some residual of this smoke may be pumped into the upper troposphere (Liu et al., 2010).

During the winter monsoonal months, fire activity in central Sumatra is still high. In this case winds flowing over the island are mostly northeasterly, with rainout occurring over 

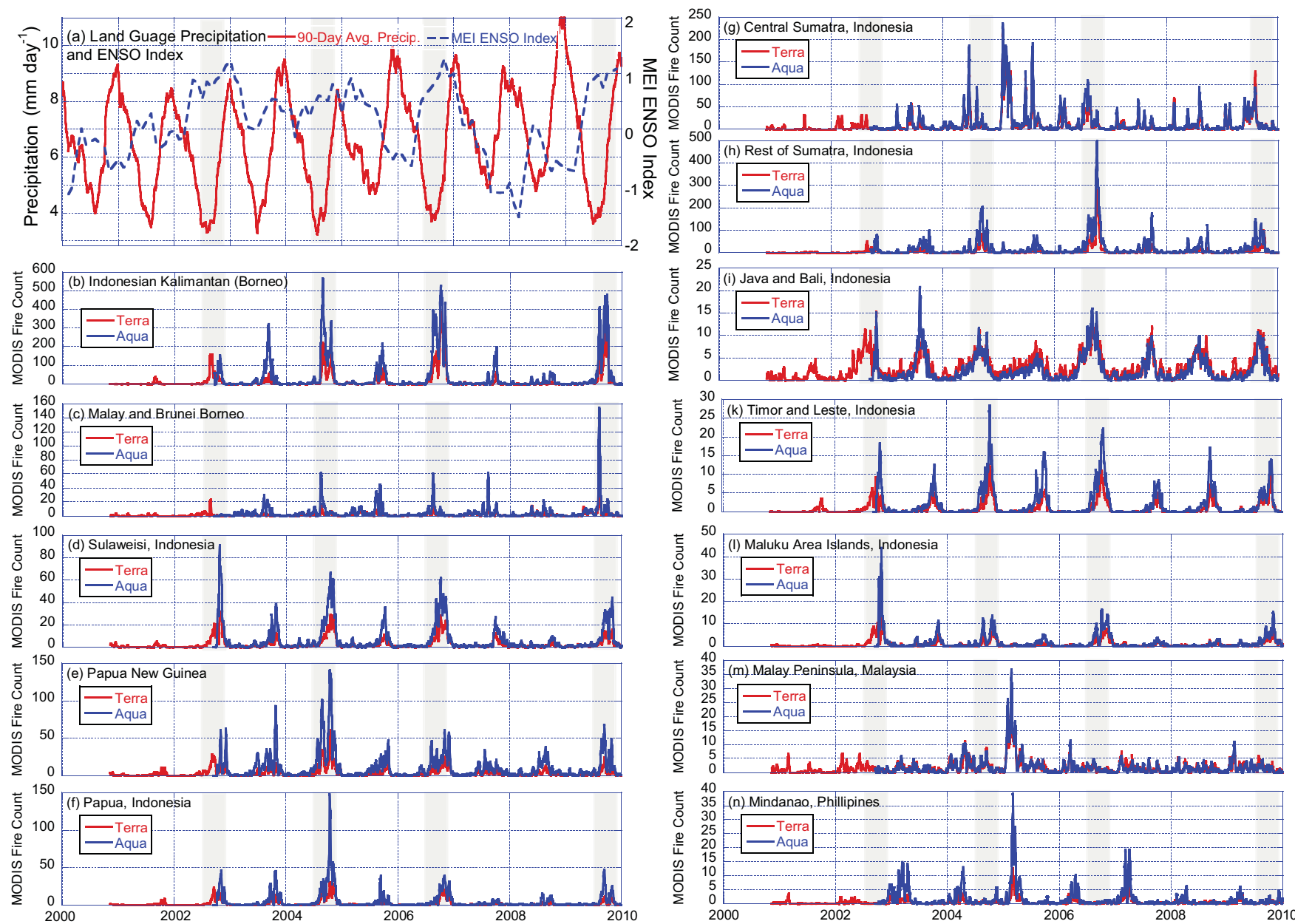

Fig. 4. Regional Terra and Aqua 9-day boxcar fire time series for key regions of the MC for 2000-2010. Also included in (a) is the previous 90 day average precipitation for Borneo (as suggested by Field et al., 2009) and the MEI ENSO Index. Positive ENSO index/warm anomaly periods for MEIs above 0.5 are grayed during the June-November burning season.

the volcanic ridge of Sumatra. Some smoke from Cambodia and southern Vietnam also appears to work its way south into the northern MC through the NW SCS monsoonal flow. However, the dominant Indochina pathway for this burning region is aloft in the westerlies into the central Pacific Ocean, with some wet deposition in convection over the mountains of northern Laos.

\section{Results - meteorological context a: interannual behavior}

Among tropical regimes, the MC shows the some of the most extreme interannual variability in fire prevalence. The nature of island specific interannual variability for the MC is well represented visually through the nearly 10 year time series of Terra and Aqua fire counts from 2000-2009 (Fig. 4). To help with the interannual signal, we began with the CPC land gauge precipitation network for the previous 90 day precip- itation for Borneo (as recommended as a threshold by Field and Shen, 2008) and the Multivariate ENSO Index (MEI) in Fig. 4a. For brevity, fire counts for some regions were combined, such as Indonesian Kalimantan (Fig. 4b), Malay and Brunei Borneo (Fig. 4c), and Java and Bali (Fig. 4i).

The island specific nature of interannual variability of fire throughout the MC is clearly seen in Fig. 4 and Table 2, (including markers for differences which fail a Students t-test at the 0.05 level). Most islands have a high interannual standard deviation, with the largest emitting regions on Borneo and Sumatra having the highest variability (68-91\%). Regions with less total burning activity such as the Southern Islands, and Timor Leste, Java, and parts of Sumatra have the lowest variability. Fire activity roughly follows the average time series discussed in Sect. 3.2, and even at this coarse scale islands with early versus late season burning can be differentiated.

The suggestion that the bulk of regional fire activity can be estimated from a running 90 day precipitation estimate 
Table 2. Impact of El Nino conditions on Fire count and precipitation rates. Fire Count Sensitivity (FCS) is the ratio of June-November total fire counts for positive ENSO index years $(2004,2006,2009)$ to all remaining negative and neutral years (2003, 2005, 2007, 2008). Also given is the relative fire ratio of the winter period leading into or lagging an El Nino event. Precipitation rate (from CMORPH, mm day ${ }^{-1}$ ), is given as the average of negative and neutral years $>$ positive years for the burning season. For comparison, CPC gauge network values for the core August and September period are given as well.

\begin{tabular}{|c|c|c|c|c|c|c|c|c|c|c|}
\hline Location & $\begin{array}{l}\text { Inter- } \\
\text { Annual } \\
\% \text { Std dev. }\end{array}$ & $\begin{array}{l}\text { El Nino } \\
\text { FCS } \\
\text { Jun-Nov }\end{array}$ & $\begin{array}{l}\text { El Nino } \\
\text { FCS } \\
\text { Winter- } \\
\text { lag }\end{array}$ & $\begin{array}{l}\text { El Nino } \\
\text { FCS } \\
\text { Winter- } \\
\text { lead }\end{array}$ & $\begin{array}{l}\text { June } \\
\text { Precip } \\
\text { Rates }\end{array}$ & $\begin{array}{l}\text { Jul } \\
\text { Precip } \\
\text { Rates }\end{array}$ & $\begin{array}{l}\text { Aug-Sep } \\
\text { Precip } \\
\text { Rates }\end{array}$ & $\begin{array}{l}\text { Oct. } \\
\text { Precip } \\
\text { Rates }\end{array}$ & $\begin{array}{l}\text { Nov. } \\
\text { Precip } \\
\text { Rates }\end{array}$ & $\begin{array}{l}\text { CPC } \\
\text { Aug-Sep } \\
\text { Precip } \\
\text { Rates }\end{array}$ \\
\hline \multicolumn{11}{|l|}{ Indonesia } \\
\hline Java and Bali & $21 \%$ & 1.4 & $1.1^{\mathrm{a}}$ & $1.0^{\mathrm{a}}$ & $1.3>0.8$ & $0.4>0.4^{\mathrm{b}}$ & $0.4>0.1$ & $3.0>1.0$ & $7.1>5.4$ & $1.4>0.7$ \\
\hline Kalimantan, Eastern & $52 \%$ & 3.0 & 1.5 & 0.7 & $6.5>7.3$ & $6.2>6.3^{\mathrm{b}}$ & $6.6>4.1$ & $9.9>5.3$ & $11.7>8.3$ & $5.6>4.1$ \\
\hline Kalimantan, Southern & $91 \%$ & 5.6 & 0.6 & 1.7 & $5.2>4.6$ & $4.2>3.3$ & $3.9>1.2$ & $10.1>4.0$ & $11.1>9.4$ & $2.3>1.0$ \\
\hline Kalimantan, Western & $59 \%$ & 3.2 & $1.2^{\mathrm{a}}$ & $0.8^{\mathrm{a}}$ & $8.5>6.3$ & $7>7.2^{b}$ & $8.1>4.5$ & $13.8>7.0$ & $12.2>12.6^{\mathrm{b}}$ & $6.4>4.4$ \\
\hline Maluku Islands & $58 \%$ & 2.9 & 0.4 & 2.3 & $5.4>5.6^{b}$ & $4.9>4.2^{b}$ & $5.4>3.5$ & $8.2>3.1$ & $6.6>5.7$ & $6.0>3.6$ \\
\hline Papua & $80 \%$ & 2.8 & 0.3 & 3.4 & $6.9>8.3$ & $6.7>5.8$ & $8.7>6.3$ & $13>7.5$ & $13.0>7.4$ & $7.0>4.3$ \\
\hline S. Islands \& Timor Leste ${ }^{\mathrm{d}}$ & $21 \%$ & 1.4 & 0.7 & 1.5 & $0.4>0.3^{b}$ & $0.1>0.1^{\mathrm{b}}$ & $0.1>0.02$ & $0.8>0.3$ & $3.4>1.3$ & $0.7>0.6^{b}$ \\
\hline Sumatra, Central & $68 \%$ & 1.7 & $1.6^{\mathrm{c}}$ & $0.6^{\mathrm{c}}$ & $5.2>4.2$ & $4.9>4.5$ & $6.4>5.1$ & $9.7>7.3$ & $9.5>8.4$ & $8.3>5.8$ \\
\hline Sumatra, Northern & $32 \%$ & 1.9 & $1.1^{\mathrm{a}}$ & $0.9^{\mathrm{a}}$ & $5.6>4.5$ & $6.4>6.3^{b}$ & $8.1>7.3$ & $11.8>10.0$ & $10.1>7.0$ & $8.3>8.3^{b}$ \\
\hline Sumatra, Southern & $78 \%$ & 3.4 & $1.2^{\mathrm{a}}$ & $0.8^{\mathrm{a}}$ & $3.4>3^{b}$ & $3.1>3.5^{\mathrm{b}} \mathrm{r}$ & $4.0>1.5$ & $7.9>3.7$ & $10.7>8.0$ & $4.0>1.7$ \\
\hline Sumatra, Westward & $35 \%$ & 2.3 & $0.8^{\mathrm{a}}$ & $1.2^{\mathrm{a}}$ & $4.3>3.2$ & $3.7>3.5^{\mathrm{b}}$ & $5.0>3.5$ & $8.5>6.3$ & $8.7>8.6^{b}$ & $10.4>8.5$ \\
\hline Sulawesi & $53 \%$ & 2.6 & 0.7 & 1.3 & $3.7>3.7^{b}$ & $3.2>1.5$ & $2.0>0.5$ & $4.0>1.2$ & $5.8>3.9$ & $2.6>1.1$ \\
\hline \multicolumn{11}{|l|}{ Malaysia } \\
\hline Malay Peninsula & $55 \%$ & 1.3 & $1.3^{\mathrm{b}}$ & $0.7^{\mathrm{b}}$ & $5.9>4.9$ & $5.6>5.2^{b}$ & $5.9>5.6^{b}$ & $8.9>9^{b}$ & $10.8>9.8$ & $6.1>6.7$ \\
\hline Sabah, Borneo & $43 \%$ & 1.6 & 2.1 & 0.4 & $6.7>7.0$ & $5.6>7.9$ & $7.1>6.0$ & $8.0>6.5$ & $6.6>4.8$ & $7.4>8.2$ \\
\hline Sarawak, Borneo & $64 \%$ & 1.9 & 0.86 & 1.2 & $10.0>5.9$ & $8.2>7.2$ & $9.0>7.9$ & $12.1>7.0$ & $9.9>12.0$ & $8.7>7.2$ \\
\hline Papua New Guinea & $52 \%$ & 1.7 & 0.5 & 1.9 & $4.2>7.4$ & $3.7>3.4^{\mathrm{b}}$ & $5.8>3.7$ & $9.6>5.2$ & $11.5>9.1$ & $4.9>3.4$ \\
\hline Philip.-Mindanao* & $45 \%$ & 1.75 & 1.7 & 0.6 & $8.1>7.8^{b}$ & $7.4>7.5^{\mathrm{b}}$ & $6.8>5.0$ & $9.0>4.4$ & $6.8>5.3$ & $7.6>6.2$ \\
\hline
\end{tabular}

${ }^{a}$ Difference in winter lead and lag is not statistically significant. We deem significance if all lead/lag years are larger/less than all lag/lead years and fails a t-test.

${ }^{b}$ Difference fails a t-test. ${ }^{c}$ The severity of the 2005 winter fire season prevents true comparison. ${ }^{\mathrm{d}}$ No CPC data in Timor Leste.

(e.g, Field and Shen, 2008; Field et al., 2009) seems relatively robust, but is by no means definitive. Drier years have the higher fire activity, but even these authors state that the 90 day precipitation should be treated as a tipping point for higher fire activity rather than a parameter from which one could form a regression equation. Our data support this interpretation.

One exception to the simple seasonal model is central Sumatra. From Sect. 3.1 we know that central Sumatra does not follow the rest of the MC's seasonal cycle, and its independence form the fire dominated regimes of Southern Kalimantan and Southern Sumatra has been noticed (Field and Shen, 2008; Tosca et al., 2011). But in Fig. 4g we see that there is almost no pattern at all, with burning events occurring any time of year except November and December. During January-March 2005, central Sumatra had large fire events with localized fire densities that rival those of the dry season. The Malay Peninsula, where fire prevalence is typically low, also had increased fire prevalence during this period. While not often discussed in the climate literature, such burning activity has been noticed by regional air quality studies (e.g., Balasubramanian et al., 2003) and in some factor analyses as offseason burning (Field and Shen, 2008).
Figure 4 shows the enhanced fire activity associated with ENSO warm phase conditions, a well studied phenomenon over Borneo and Sumatra (e.g., Nichol, 1998; Siegert et al., 2001; Parameswaran et al., 2004; Langmann and Heil, 2004; Fuller et al., 2006; Field and Shen 2008; van der Werf et al. 2004,2008; Langner and Siegert 2009; Field et al., 2009; van der Kaars et al., 2010). Indeed, from a total fire count or emissions point of view, El Nino dominates the interannual signal, especially those studies which include the massive 1997 event. Recently, other secondary modes of the Indian Ocean Dipole (IOD) and El Nino Modoki are receiving wide attention. It is thought that these modes influence MC meteorology through shift in very large scale features, such as the Walker circulation and the location of the monsoonal trough. These in turn can impact regional winds, tracks of tropical cyclones and tropical waves, regional large scale subsidence and ultimately precipitation. These indices are presented in Fig. 5. Even though our core study period encompasses the 2003-2009 period, we present index data to 1996 to provide context to other studies in the literature. As meteorological modes, they are nominally uncorrelated over long time periods. But examination of Fig. 5 shows that over several years these modes exist in or out of phase (e.g., ENSO and IOD in 


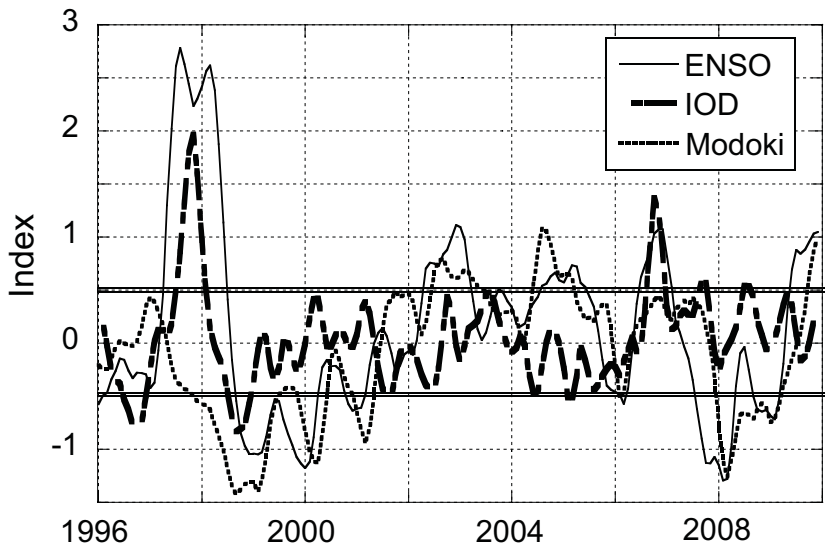

Fig. 5. 1996-2009 time series of the Wolter and Timlin, (1998) ENSO MEI Index, the Saji et al. (1999) Indian Ocean Dipole Index (IOD), and the Ashok et al. (1997) Modoki Index.

1997 and 2006, or ENSO or Modoki 1999-2005). These are discussed in the following subsections.

\subsection{ENSO}

Much of the interannual fire variability seen in Fig. 4 is correlated to ENSO warm phase. This agrees with the McBride et al. (2003) finding that during boreal summer precipitation over the MC is negatively correlated with an ENSO index. For typical El Nino events, the MEI rises above 0.5 in the boreal spring to early summer and persists through the following winter. The fire season corresponds to the boreal late summer and fall in this period. Over the past ten years, El Nino conditions (MEI $>0.5$ ) occurred during the core JuneNovember burning season in 2002, 2004, 2006, and 2009 (often the following winter year is associated with El Nino events, e.g., 2003, 2005, 2007, 2010). Over the past $20 \mathrm{yr}$, the 1997 El Nino fire event still dominates signals and hence any unsupervised statistical analysis. During our core 20032009 study period, El Nino is the dominant factor in total fire activity.

To quantify ENSO effects we generated a relative index of fire count sensitivity (FCS) through the ratio of the 2004, 2006 and 2009 warm ENSO years, to the cold and neutral ENSO years of 2003, 2005, 2007 and 2008 (i.e, ratio of El Nino to non El Nino years). Just as in Field and Shen (2008), our internal analysis indicates that cold and neutral phases as indicated by the MEI can be lumped together for fire anomalies. This gives a relative El Nino enhancement of fire activity with statistics in Table 2. Also included are the average precipitation rates for cold and neutral versus warm ENSO years for the months preceding, during and after the fire season. All islands show some increase in observed fire counts during El Nino, with the previously documented dominant emitters of Indonesian Kalimantan, Borneo and southern Sumatra showing the strongest sensitivities with increases in factors of $\sim 3-5$ in observed fire prevalence. Sulawesi, Maluku and many parts of Sumatra show a factor of 2-3 sensitivity. All other island regions show around 50\% warm phase sensitivity.

From a meteorological point of view, El Nino sensitivity is related to precipitation deficits as described from rain gauge data in the papers cited above. Regionally however, the process is best elucidated from Fig. 6, where we show CMORPH precipitation and $850 \mathrm{hPa}$ winds anomalies for warm phase and cold/neutral phase versus all other years. These anomalies suggest the eastward extension of the summer monsoonal trough away from the MC during the ENSO warm phase. The eastward extension in the monsoonal trough and the Walker circulation introduces anomalous subsidence over the MC. El Nino also results in cooler waters around the MC, which may reduce over water convection or latent heat flux. Indeed, during La Nina positive SST anomalies are located upstream of enhanced convection over the MC (McBride at al., 2003). As the onset of an El Nino is in the boreal spring, an earlier onset vs. a late onset may make differences in MC rainfall anomalies. This is not reflected in the MEI index, which showed no relationship between onset date and fire severity.

During our observed El Nino events, precipitation is 2 to $3 \mathrm{~mm}$ per day lower over the MC for the core burning periods. Some precipitation deficit is visible for warm phases for the entire season (Fig. 6e, f). ENSO-related precipitation deficits over ocean are roughly half that from over land, but we cannot exclude the possibility that this is related to algorithmic biases in the CMORPH product. These satellite derived numbers also are in good relative agreement with the CPC land gauge network presented in Fig. 4a and Table 2, although a clear shift in magnitude is visible. A rainfall deficit of $1-3 \mathrm{~mm}$ per day averaged over the region by many standards does not seem excessively dry, however it does represent a $20-50 \%$ rainfall reduction for El Nino periods, or roughly $20-25 \%$ of the winter monsoonal precipitation rate.

While there are significant shifts in precipitation, climatological winds over the MC appear to be unaffected, with virtually no modeled impact in the core August-September burning season in South China, Java and Celebes Seas. However taken over the whole June-November burning season, impact is seen on the borders of the MC. In the vicinity of the monsoonal trough in the western Pacific, $850 \mathrm{hPa}$ wind anomalies are quite strong.

Off season burning is also sensitive to ENSO phases, as shown in Fig. 6e and f, where we show precipitation anomalies in the boreal spring leading into and out of a El Nino event. Statistics are included in Table 2. Some islands show a very distinct enhancement in burning activity in the boreal spring following an El Nino event, such as some regions in Kalimantan, as was reported in the 1997 El Nino event. This also appears to be true for Mindanao as well. In general, island regions, particularly in the southern part of the domain, have precipitation deficits in the winter monsoon 

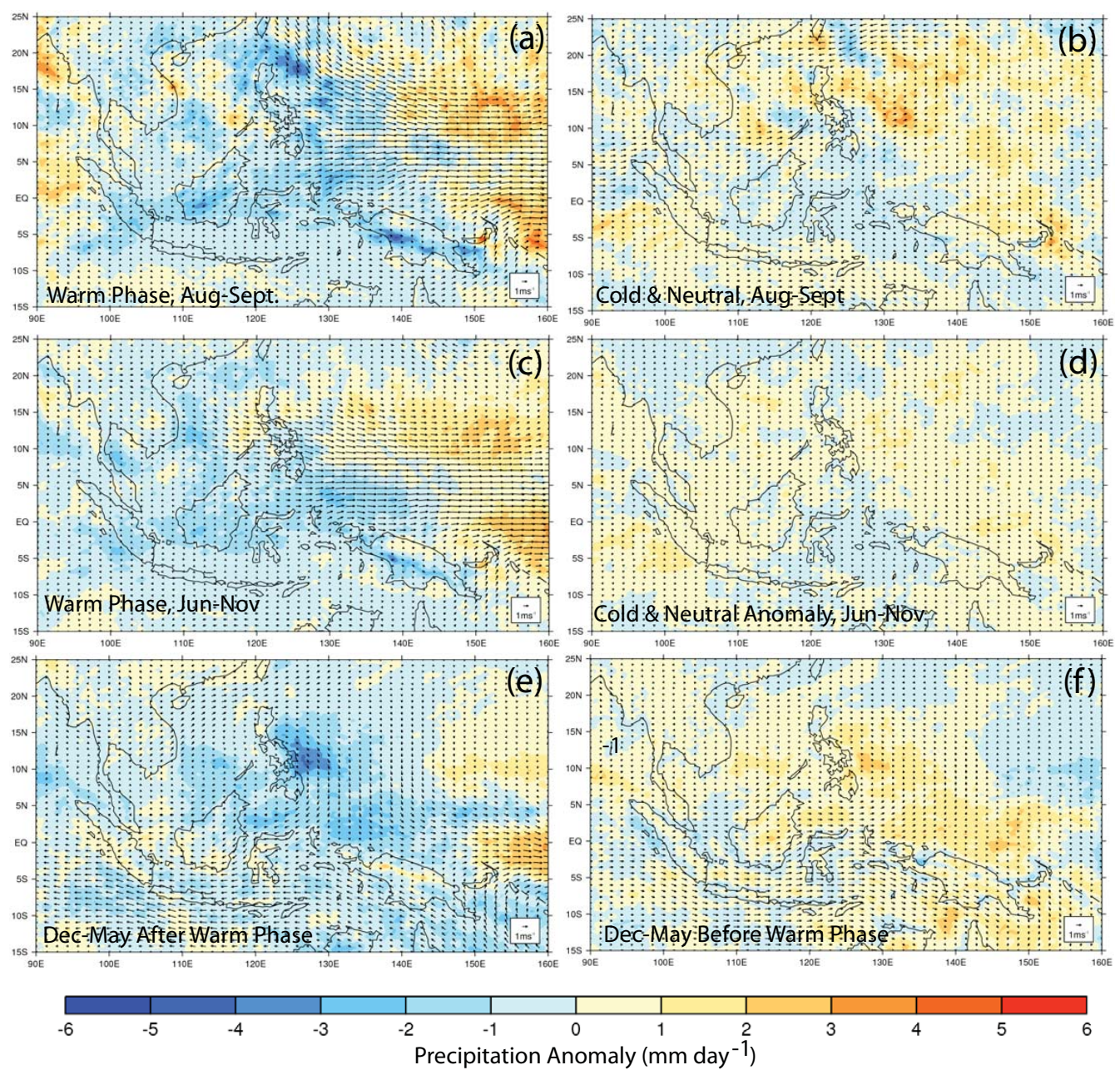

Fig. 6. CMORPH derived ENSO related precipitation anomalies for the Maritime Continent. (a) and (b) Warm El Nino and Cold \& Neutral phases precipitation anomalies for the peak August and September burning season, respectively. (c) and (d) Warm and Cold \& Neutral phases for the total June-November burning season, respectively. (e) and (f) Boreal winter and spring precipitation anomalies for the ENSO warm phase and the period leading into the warm phase, respectively.

associated El Nino events. Our examination of fire data as well as both the CMORPH and CPC data shows a general propensity for enhanced fire activity and precipitation deficits in East Kalimantan in the spring leading out of an El Nino event. Other islands show heightened boreal spring burning leading into an El Nino fire season, particularly in Southern Kalimantan and the eastern MC. Central Sumatra in January-February 2005 showed a massive fire event rivaling the dry season. Technically, the MEI dropped below 0.5 for these two months, but was bookended on either side above the threshold. Papua Indonesia and Papua New Guinea interestingly have tendencies opposite what one would expect - precipitation and fire activity are enhanced in the spring leading to the El Nino event.

\subsection{Indian Ocean Dipole}

Statistical and EOF analyses of interannual precipitation and fire behavior always key on the dominant ENSO signal. However, over the last decade additional modes have been identified, most notably Indian Ocean Dipole (IOD, Saji et al., 1999; Saji and Yamagata, 2003; Schott et al., 2009) and as discussed in the next sub section, El Nino Modoki (Ashok et al., 2007). In EOF analyses ENSO and these secondary modes are "orthogonal" to one another. However, the complexity of Indian-Pacific Basin dynamics leaves open possibilities that they may in part be interrelated. For context, Fig. 5 presents the ENSO, IOD and Modoki indices from 1996-2009. We use a longer time series to include the outside 1997 signal which has dominated previous statistical analyses in the literature. 
The positive IOD represents a dipole pattern of anomalously low and high SST off Sumatra and in the western Indian Ocean, respectively. It is hypothesized that during periods positive IOD, anomalously high easterly winds across the MC and central Indian Ocean, shear stress on the ocean surface results in warmer waters in the western Indian Ocean, and upwelling of colder water on the eastern shore of Sumatra. This SST reduction may reduce regional convection.

While the IOD and its teleconnection patterns have received considerable attention in the literature, there is remarkably little published information directly on its impacts on the MC. In the original paper by Saji et al. (1999) it is suggested that strong positive IOD results in a shift in the Walker circulation and subsequently negative precipitation anomalies in Sumatra, Indonesian Kalimantan, and Java. However correlations of IOD to precipitation anomolies in the most active burning regions save southern Sumatra were not found to be statistically significant. Recently Annamalai (2010) found results supportive of Saji et al., (1999) that during a strong IOD the summer monsoon in the eastern Indian Ocean, south of the Sumatran Low, experiences belownormal rainfall while along the monsoon trough rainfall is enhanced. But looking at longer time series, Annamalai et al. (2010) suggested that the presence of a positive IOD during a developing El Nino event increases El Nino strength (although this relationship would also manifest itself in the ENSO index). This may indirectly impact precipitation and fire activity in the MC.

In the statistical analysis by Field and Shen (2008), IOD was found to be a factor in fire activity in terms of its effect on precipitation. They stated that "The most severe drought and fire events appear equally influenced by Indian Ocean Dipole events and El Nino events". In their unsupervised statistical reduction, strong IOD events occurred in 1997 and 2006 both strong El Nino events and the largest fire events of the past $15 \mathrm{yr}$ (see Fig. 5). Indeed, for our own core time series, 2006 clearly had the highest burning activity. A key question then is what is the nature of the relationship between the IOD and interseasonal precipitation and fire patterns?

In a personal communication related to the present paper, Field pointed out Hong et al. (2008) reported that for the period of 1948-2002 that the strongest negative precipitation anomalies in the MC for June, July, August have occurred during periods of combined positive ENSO and IOD indices. In his own personal communication with Hong (2011), Field reported that the same was true for September, October, and November. However, examination of the time series of Fig. 5 yields some interesting behavior previously unnoticed. In the two most significant 1997 and 2006 events, the IOD index spikes in late and early October, respectively-after the burning season showed significantly enhanced observed fire activity. This leads to questions regarding cause and effect as well as potential changes in the monsoonal cycle (This is discussed in more detail in Sect. 5). Is the IOD spike a result of the conditions brought on by ENSO, or is it representative of a more independent factor which conspires to decrease precipitation and enhance fire activity? Regardless, given our limited analysis period we cannot perform a rigorous evaluation, only note that the large El Nino events and IOD events appear to be related, especially during boreal Fall. The relationship between the IOD and ENSO appears to be complex, with Cai et al. (2011) reporting that ENSO explains relatively little of the variance of the IOD during boreal summer $(17 \%)$, but a much greater percentage during boreal Fall (52\%). Indeed, recently Dommenget (2011) suggested that the IOD can be largely explained by ENSO plus red noise. Clearly, observation of the timing of large IOD spikes after strong EL Nino events is supportive of some relationship between ENSO and the IOD. However, the exact mechanism and causal attribution is an area of much scientific debate.

\subsection{El Nino Modoki}

In addition to the IOD, El Nino Modoki phenomenon has recently been systematically characterized (Ashok et al., 2007). Modoki events, translating from Japanese as "Similar but different," represent a phenomenon of positive SST anomalies in the Central Pacific. Modoki events can be thought of as a warm ENSO event which begins in the Central Pacific rather than the west coast of South America. Like El Nino, Modoki events appear to increase surface pressure over the MC and be negatively correlated to summer monsoon precipitation there (Ashok et al., 1997). However, Ashok et al., also found higher surface pressure over the MC lags a Modoki event by up to 9 months. In the last decade positive Modoki has been found in 2002-2003, 2004-2005, and 2009-2010. An extreme central Sumatra and Malay Peninsula event of 2005 corresponded to the peak of the 2004-2005 event which as discussed in the last subsection, bookended by positive MEI. These indices indicate that 2001, 2007 and 2008 are the only years in our core analysis period without either El Nino or El Nino Modoki, which also have the lowest fire years for the Terra time series. Indeed, for MODIS on Terra (the longest fire record in this study) annual fire counts over Indonesia for El Nino (2002, 2004, 2006, 2009), El Nino Modoki (2003, 2005) and "neutral" (2001, 2007, 2008) are $\sim 18000,10500$, and 5500 respectively. Even though this is a short time series, fire activities in all El Nino years were more active than in all Modoki years, which were in turn all higher than all neutral years. This result is suggestive of a Modoki influence, but research using a longer time series is required.

\section{Results - meteorological context b: interseasonal impacts on seasonal cycles}

The previous section clearly demonstrates the connection between interannual tropical modes and observed fire prevalence. In this section we revisit the basic monsoonal 

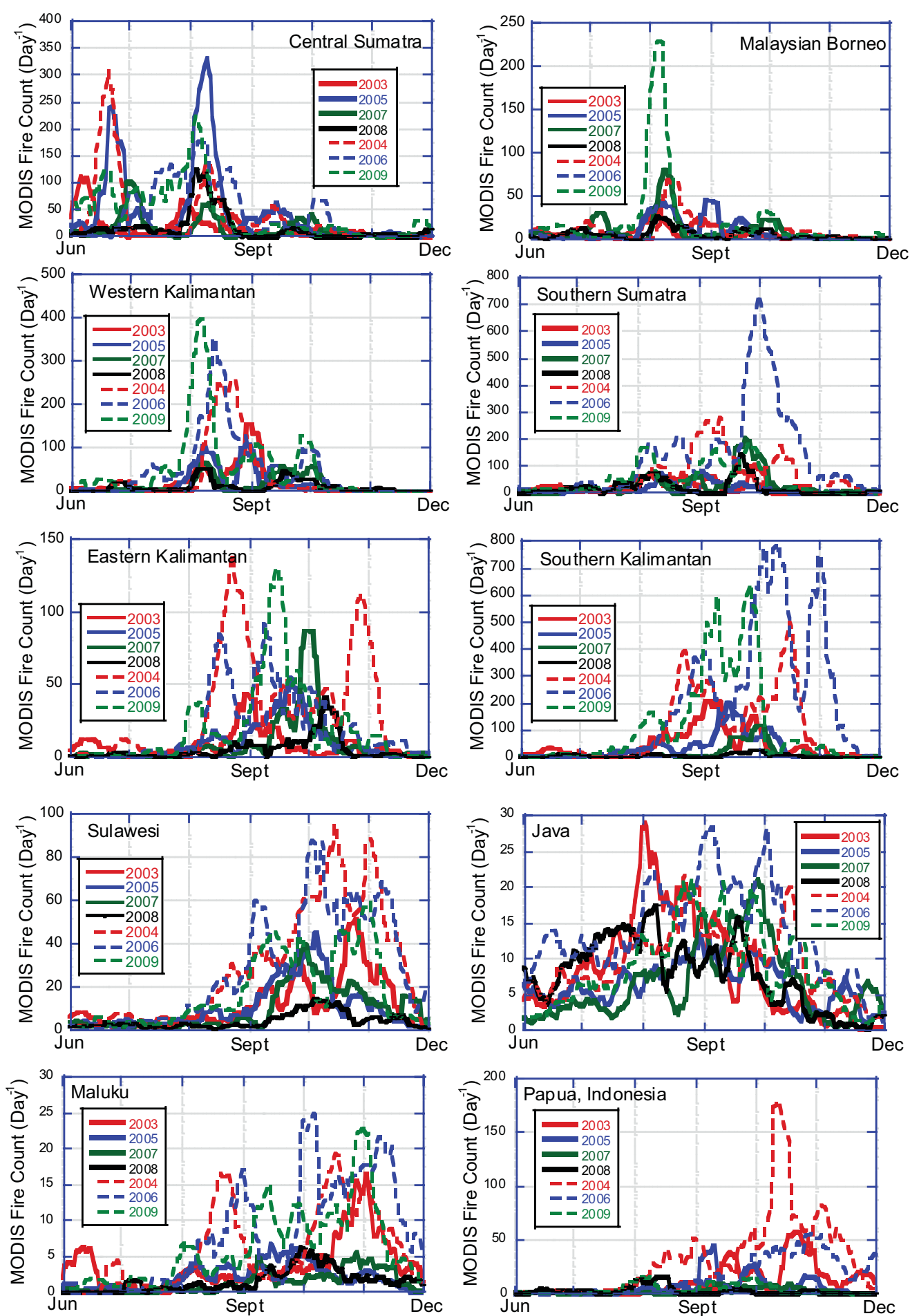

Fig. 7. 9 day box-cared MODIS fire counts for the 2003-2009 period grouped by region. El Nino years are dashed.

seasonality of MC fire and smoke behavior in the context of previously described interannual variability. Figure 7 shows smoothed daily Aqua MODIS fire counts for selected regions for the MC burning seasons of 2003-2009. Years are segregated into ENSO cold/neutral (solid) versus warm phases (dashed). Figures are ordered from those regions with the earliest burning season to the latest with a general progression from the west eastward. Significant fire events occur typically once or twice per season for low fire count years, and two to three times for more active years. 


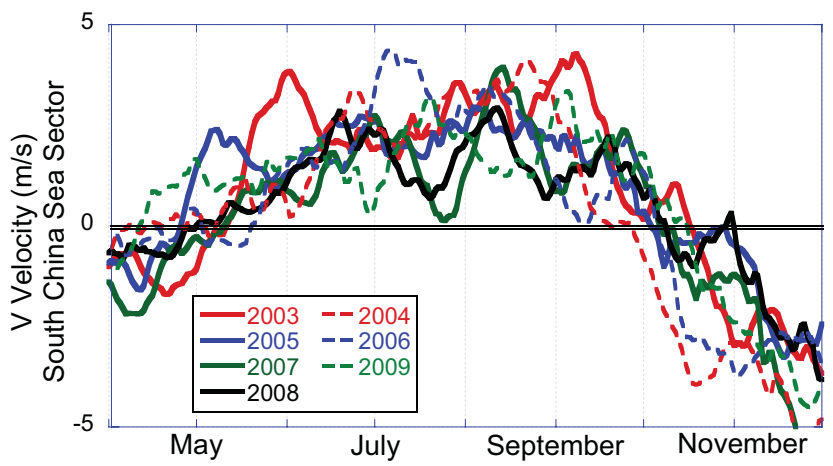

Fig. 8. 21 day box-cared meridian velocity average over the South China Sea average over the box of $5-10^{\circ} \mathrm{N} ; 109-114^{\circ} \mathrm{E}$. (positive is southerly winds).

As discussed in the previous section, in all cases El Nino years have increased fire prevalence over neutral or cold phase starting from the very beginning of the burning season (the exception is central Sumatra in 2005). At the same time, the relationship between ENSO and the start of the first major fire outbreak appears to be quite different for each region. Regions such as southern Kalimantan-Borneo, Sulawesi and Maluku with significant deforestation burning coupled with peatland burning have both an earlier start and later end to fire activity in the 2004 and 2006 El Nino burning seasons. This is suggestive of an early fire season coupled with fires burning out of control (e.g., Miettinen et al., 2009). For the 2004 El Nino and 2006 El Nino+IOD events, burning in high fire prevalence regions associated with peatlands such as in Kalimantan and southern Sumatra continues into November, well past the climatological mean ending date. The burning season in 2009, however, shows the more typical end date of early October. Other fires such as those in central Sumatra and Malaysian Borneo are remarkably consistent in modal behavior on the scale of weeks suggestive of relative dominance of agriculture and social factors. Western Kalimantan also has a strong ENSO signal, particularly early in the season, although there is not a significant shift in timing.

We can examine these seasonal issues further by inspection of precipitation data in Table 2 coupled with seasonal monsoonal timing data. Given the dominance of burning on Sumatra, Borneo and Sulawesi, we begin with the position of the monsoonal trough in the SCS. Following the logic of Lu and Chan (1999) we plotted 21 day boxcar means of meridional winds in the SCS in Fig. 8. Migration of the monsoonal trough from the winter to summer states should be indicated by a shift from the north-easterlies to the south westerlies, and visa versa. For statistical purposes, here we define the transition into and out of the summer monsoonal state as the last time for the season the meridional wind reverses sign. Perturbations in the strength of the meridional wind are related to the strength of the monsoonal trough. At first inspection, there does not appear to be any correlation between overall start date of the monsoonal migration to the summer phase, precipitation, and fire activity in the western MC. In fact, the 2009 and 2006 El Nino years with the highest overall fire activity have the earliest (10 April) and latest (May 19) springtime migration, respectively, with 2004 in the middle (7 May). But the 2004 and 2006 meridional winds were weakly negative for 2 months prior to the actual monsoonal transition, thus suggesting a weak wintertime transitional monsoonal period.

This leads us to question whether the overall monsoonal strength may be related to the start and end of the fire season. Here too the picture is mixed. In general, the average meridional winds were not correlated to ENSO strength or fire activity in the core period of fire activity (this is visible in Fig. 6). However, we did notice one interesting feature-for the El Nino years of 2004 and 2006, migration of the summer monsoon back to the winter position happened earlier and the winter monsoon phase winds in the SCS was stronger than is typical (26 September and 5 October, respectively). Yet, significant fire activity continued in Southern Sumatra, Eastern and Southern Kalimantan, Java and Sulawesi after the apparent monsoonal shift through October and in some cases into November.

At this point we can only speculate as to the nature of post monsoonal burning. Referring back again to the IOD, 2004 was IOD neutral, while 2006 was strongly positive, yet both seasons showed significant post monsoonal burningthus suggesting the 2006 IOD event may not be a dominant factor. Finally, examination of the NCAR reanalysis for the 1997 event (not shown) suggests strongly negative meridional wind anomalies in October 1997 over the SCS as well. However, should consider that during the monsoonal transaction the monsoonal trough is developing in a region of subsidence. As discussed in Sect. 3, the winter monsoon generally starts in the west and propagates eastward (Moron et al., 2009). Hence, Maluku, Timor, Papua, etc. always have burning after the monsoonal shift in the fire dominated islands of Sumatra and Borneo. Hence it is not as strong in the winter. Local forecasters suggest that drier air coming from Australia robs the transitional monsoonal trough of moisture. This allows not only fire to continue past its climatologically season end, but also dramatically changes smoke transport patterns. Typically Borneo smoke is carried into the SCS by southwesterly monsoonal winds, this late season burning is influenced by flow reversal and northeasterly winds. The resulting transport pattern brings smoke across the Malay Peninsula and Sumatra and into the Indian Ocean. Indeed, the radiation flux studies by Davidson et al., (2004) and Rajeev et al. (2008) for the 1997 El Nino Event reflect this anomalous pattern. 


\section{Results - meteorological context c: the Madden-Julian pscillation}

Cascading down time scales from interannual and seasonal scale phenomena, the next feature we discuss is the intraseasonal 30-90 day Madden Julian Oscillation (MJO, Madden and Julian, 1971, 1972). The literature review of the MJO by Zhang (2005) provides an overview of the characteristics of the MJO, but for the purposes of this study, we derived the following synopsis of aerosol relevant features from Zhang (2005) and the numerous citations within it. The MJO is a large scale, coupled pattern of the circulation and deep convection which forms in the Indian Ocean and propagates eastward at $\sim 5 \mathrm{~m} \mathrm{~s}^{-1}$ through and around the MC and into the Pacific Basin. Once this convective region passes into the central/eastern Pacific and decays, a new event may start in the Indian Ocean, thus repeating the cycle. Subsidence, and consequently negative precipitation anomalies, leads and lags this convective region, with the more dominant subsidence being observed on the eastern side when the convective region is in the Indian Ocean and on the western side when the convective region is in the Pacific. Eight phases of the MJO can be defined through two leading Empirical Orthogonal Functions (EOFs) of combined outgoing longwave radiation (OLR) and 200 and $850 \mathrm{hPa}$ zonal winds (Wheeler and Hendon, 2004). Phase 1 is associated with MJO genesis. In Phase 2 and 3, the convective regime is present over the Indian Ocean. By Phase 4 convection approaches MC and by phase 5, convection is entering the Pacific Ocean, and significant drying begins over the MC. During phase 6 and 7, it is propagating through the Pacific Ocean with maximum drying in the MC, ultimately terminating in phase 8 . The amplitude of the MJO is the strongest in boreal winter and early boreal spring with a secondary maximum in boreal summer (Zhang and Dong 2004). In the boreal summer the convection associated with MJO propagates eastward and northward, contributing to the Asian monsoon active and break cycles. With its 30-90 day cycle, we can expect 1-2 MJO cycles to occur during any fire season. In regards to El Nino, there is no simultaneous correlation between the MJO and ENSO SST, but the MJO is usually stronger prior to the El Nino peak (Zhang and Gottschalck, 2002).

While the MJO's basic phenomenology has been put forth in conceptual models based on increasing observations, there are large knowledge gaps as to the mechanisms for its formation and propagation-particularly across the MC with its high and complicated terrain. Studies such as Tian et al., (2008) have tried to look for connections between enhanced AOD and MJO phase, but face significant observability challenges related to MJO activity-particularly cloud induced biases in satellite retrievals. But given the strength of the MJO, we expect there to be some relationship between such parameters as observed fire prevalence, transport and deposition. To investigate this relationship, we assessed observed fire and precipitation activity across the MC related to MJO phase.
Given the complexity of tropical convection with its many multiscale interactions with atmospheric circulations, and given that MJO phase indices are diagnostic against satellite observations and model analyses, there can be considerable noise in the MJO signal. For our study, the Wheeler and Hendon (2004) index used to calculate MJO phase and amplitude (normalized by its standard deviation) was smoothed with a 7-day running mean algorithm. From this, we evaluated regional fire signals in a multitude of ways. The MJO index gives a phase and amplitude based on the relative strengths of two leading EOFs. Hence, every day was assigned a phase regardless of MJO amplitude, although no evident MJO is present for amplitudes smaller than 1 . To begin, we compared the June through November fire count signal for each MJO phase to the mean for the study period for all days. Next, we compared for only those days with MJO amplitudes greater than 1. Given that the MJO should be treated as discrete, pulse-like events (Yano et al., 2004), and that the MJO index can be "contaminated" with the influence of equatorially trapped waves (Roundy et al., 2009), we also did a hand selection; including only events in which more than half of the days had amplitude above 1 and showed the characteristic $5 \mathrm{~m} \mathrm{~s}^{-1}$ eastward propagation. Finally, given the dominance of the ENSO signal in overall seasonal fire activity, we repeated the calculations for El Nino and Non-El Nino years.

In Fig. 9a-d we present the relative total MODIS fire and CMORPH precipitation signals against MJO phase for two key biomass burning regions: Central Sumatra and all of Indonesian Kalimantan on Borneo. Error bars represent standard errors of the phase means. In both of these cases, clear MJO signals are present. As expected from the meteorology, fire minimums and precipitation maximums are in the early phases when the active phase of MJO is located over the Indian Ocean and the MC, with fire maximum and precipitation minimums in the later phases after convection propagates into the western Pacific. The reduced fire count during phases 1-3 when the maximum convection is located over the central Indian Ocean could be explained by precipitation developing in ahead of the main MJO "envelope" - either from fast propagation Kelvin waves or the orographic precipitation related to prevailing easterlies. Central Sumatra shows a higher sensitivity (a factor of 5 trough to peak) than Indonesian Borneo-Kalimantan (a factor of 2 to 3 ). These sensitivities are extremely robust; categorization based on phase alone is nearly identical to hand selection of strong MJO events. This co-linearity demonstrates the simple precipitation-fire activity relationship. Any diagnostic indicator which is related to precipitation will in some way be anti-correlated with observed fire activity-whether it is related to the MJO or not.

The most interesting finding from this analysis perhaps is that the El Nino and non-El Nino curves show only statistically insignificant differences. Performing a similar analysis for the wintertime monsoon also produced remarkably similar results. This suggests that overall the MJO modulates 

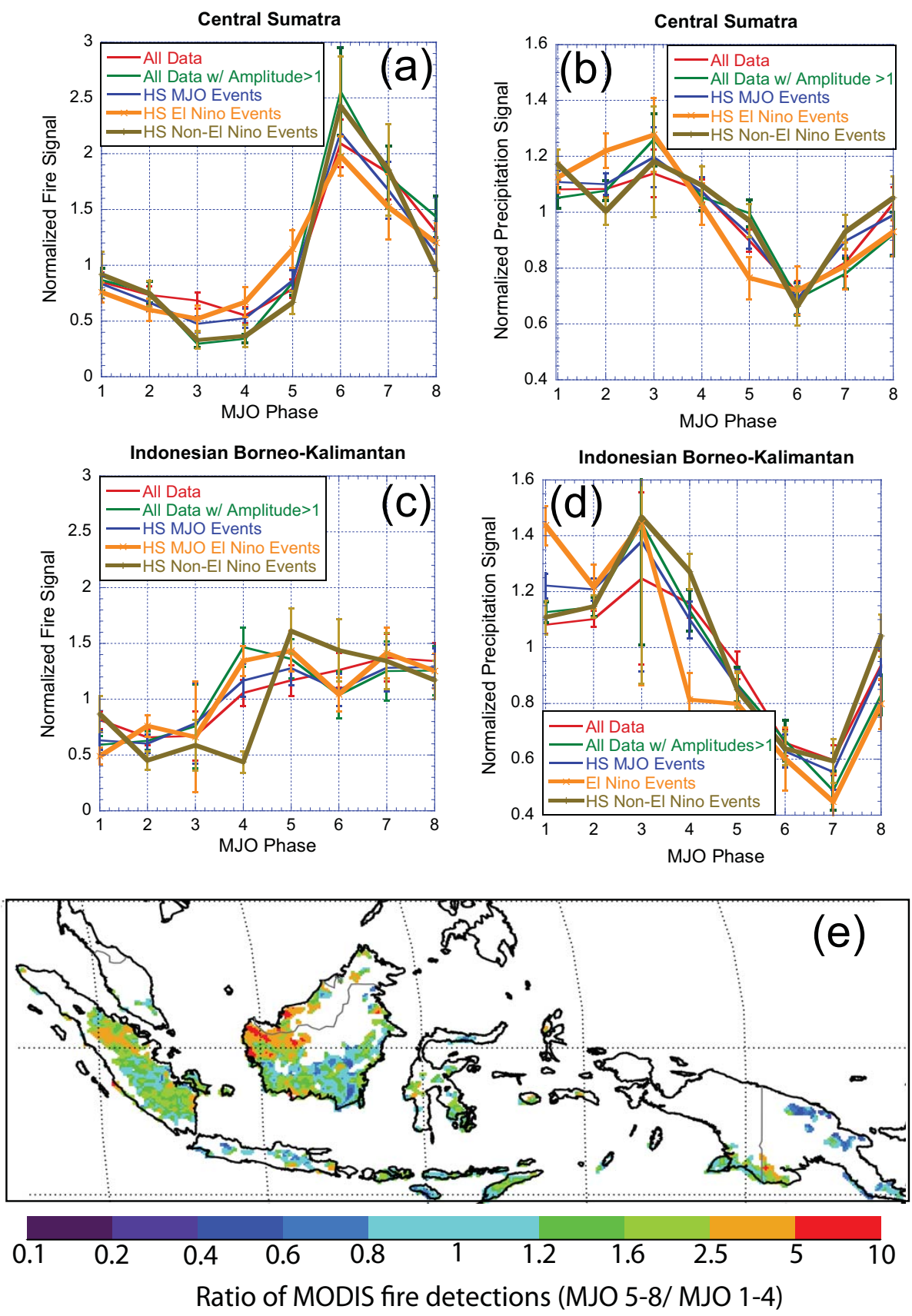

Fig. 9. Summary observed fire and CMORPH precipitation statistics by MJO phase. (a) The ratio of observed MODIS fire counts for well developed MJO phases 5-8 over phase 1-4 for the June-November burning season. (b) Normalized precipitation signal as a function of MJO phase for central Sumatra segregated by MJO Amplitude and El Nino conditions. (c) and (d), same as (a) and (b), respectively but for all of Indonesian Borneo-Kalimantan. (e) special map of June-November ratio of fire detections for MJO phases 5-8 over 1-4.

observed fire activity, but is not as strong in affecting the total seasonal fire count, which is dominated by region wide ENSO-precipitation relationships.

We performed an MJO analysis over the entire MC, and summary findings are presented in Table 3. In Table 3, we present the regional peak and trough phase and relative strength for our hand selected MJO events during the pri- mary burning season (June-November). Two sets are given, corresponding to all burning season data in our 2003-2009 core study period, as well as isolating data from the 2004, 2006 and 2009 El Nino events. Overall, we see the influence of the eastward propagating MJO, with peak fire generally occurring in phases 5, 6 and 7 after the convective region has passed. The furthest eastern islands of the MC, 
Table 3. Impact of MJO on observed fire count and satellite precipitation rates in the June-November Time frame. Statistics are generated for only periods of distinct MJO events as defines in the text. Data is separated for MJO events during the entire focus period (2003 through 2009) as well as for years excluding the 2004, 2006, and 2009 El Nino Events. Provided for each category is the corresponding maximum phase : and relative amplitude for that phase to the mean. For bimodal cases, two values are given.

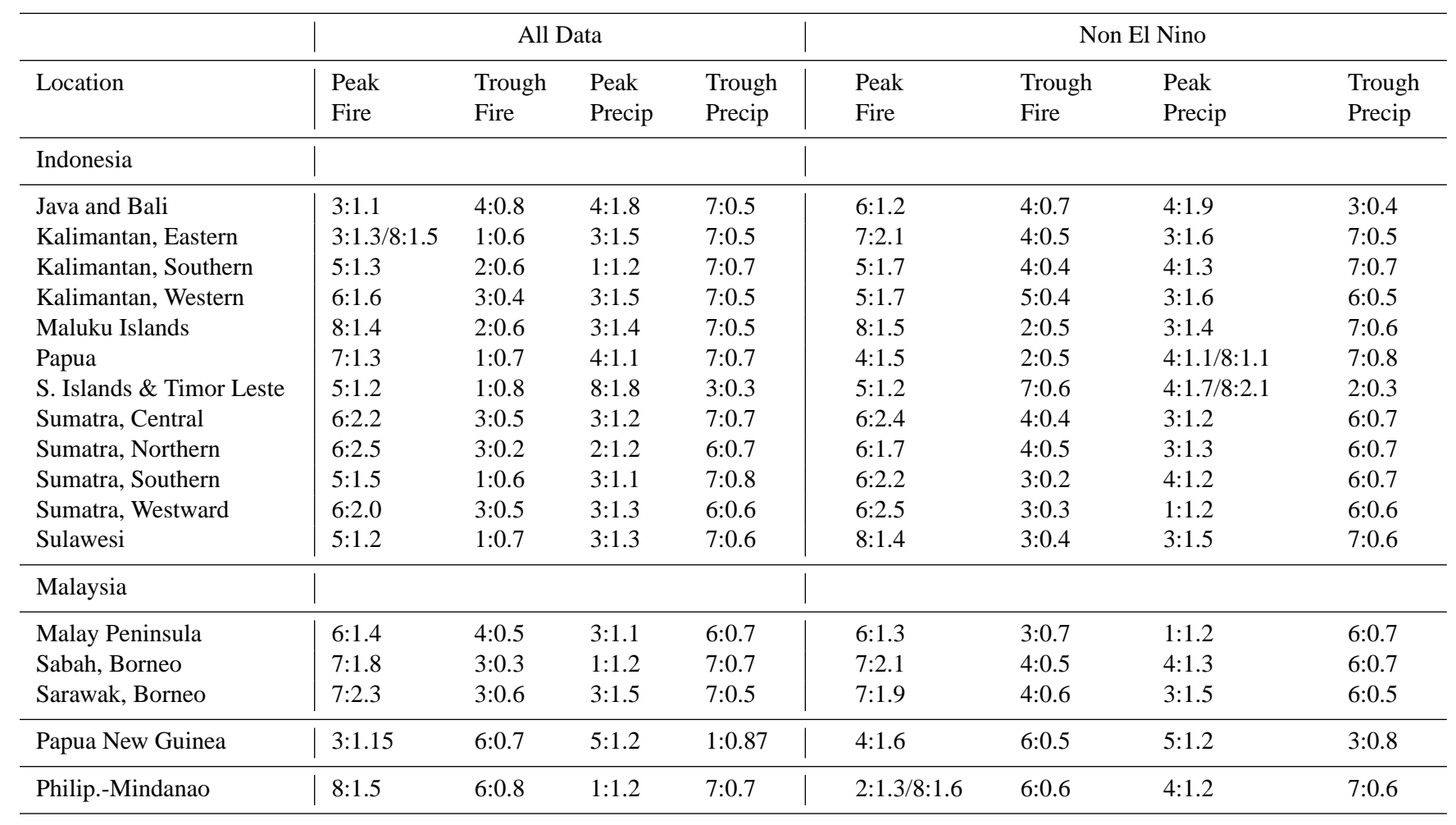

such as Papua New Guinea, see maximum drying ahead of the convective region. Islands with little or no precipitation during the dry season (e.g. Java or Timor) have the smallest sensitivity $(\sim 20 \%)$. Regions with the highest orographic features and hence overall enhanced convection, such as on Sumatra or the western side of Borneo (Western Kalimantan, Sabah and Sarawak), have the highest total sensitivity (peak to trough is a factor of 3 to 5). When we inter-compared MJO phase with the peaks and troughs in Fig. 7 we found that while peaks in fire activity are often associated with strong MJO events in later phases, more often it is the minima in observed fire activity being associated with phases 2 and 3 which dominates the MJO observed fire activity relationship. For example MJO phase 2 always decreases fire activity in the Kalimantan and Sumatra regions during El Nino years.

The spatial sensitivity to the MJO is illustrated in Fig. 9e where we plotted the ratio of the observed fire signal for phases 5-8 over phases $1-4$, every $1 / 4$ degree, for those regions which had sufficient fire activity for statistics to be calculated. Here, coherent patterns emerge, with very high sensitivities (factors of 5-10) in Central Sumatra and the most western portion of Borneo. These areas are notable for their use of agricultural burning (e.g., see maps of Miettinen et al., 2008) and orographic influence). Areas highlighted by Miet- tinen et al as having persistent peat burning as we expect do not appear to have as strong of an MJO sensitivity $(<50 \%)$. These peat fires are tied to underlying hydrological factors and hence are more sensitive to the 90 day precipitation field as described by Field and Shen (2008). Further, it also appears that peak MJO phase is typically one phase later than regions of agricultural burning. This is most likely a fuel drying effect, although more research is needed to determine whether it is mediated by ignition or fire spread.

We repeated this calculation for the non-burning December-May time period, when MJO events have maximum strength. Results (not shown) are very similar to those of the burning period, but with two key differences: (1) maximum fire activity is delayed by one to two phases, and (2) due to stronger precipitation, troughs in fire activity are much lower than during dry seasons, effectively doubling the relative differences between troughs and peaks. In some isolated cases, such as western Kalimantan, Borneo, the peak to trough ratio can be an order of magnitude. The short time series and low levels of burning in the wet season limit the quantitative description of these relationships in the current study. 

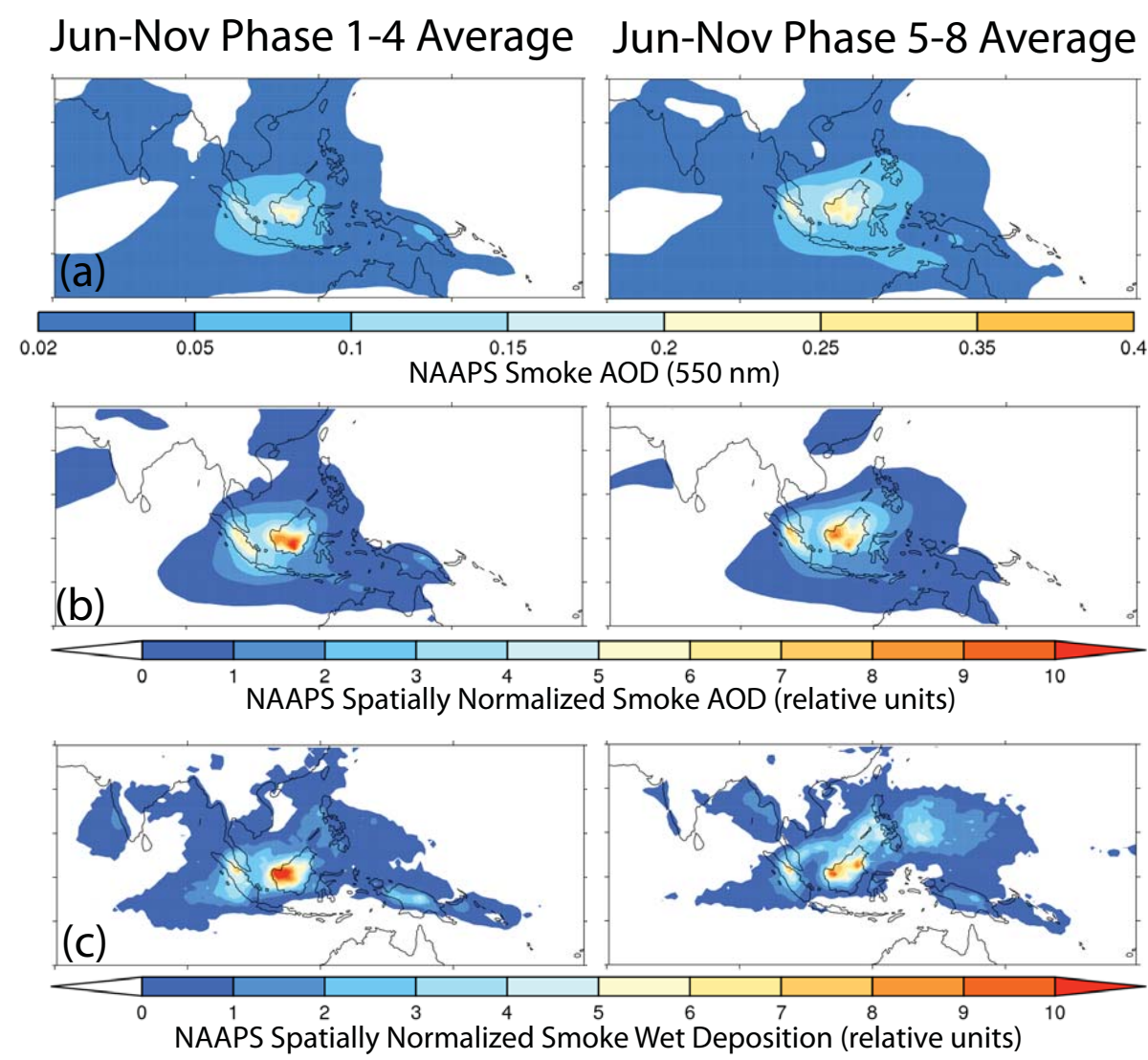

Fig. 10. For June-November burning season, NAAPS smoke statistics for MJO phase 1-4 and 5-8. (a) Total smoke AOD; (b) Spatially normalized AOD; (c) Spatially normalized smoke wet deposition.

As per our discussion above, we expect the MJO's influence on fire activity would also affect smoke life cycle. Given the clear anti-correlation between precipitation and fire activity, we would expect higher AODs and farther smoke transport in the later phases. This is presented in Fig. 10a, where we provide dry season AODs averaged for MJO phases 14 versus $5-8$. Like our previous analysis, here we only use cases which we hand analyzed as specific MJO events with an average amplitude $>1$ and a clear eastward propagation. Not only is fire activity impeded in early phases due to precipitation, wet deposition is also enhanced. Less precipitation and increased westerly flow in later phases (Zhang, 2005) means smoke is likely to be transported further. Figure 10a shows elevated smoke AODs intruding slightly further into the monsoonal trough. But more dramatic differences are seen in the relative distribution of the NAAPS modeled wet deposition (Fig. 10c). In early MJO phases, smoke does not travel far from the source, with dominant sinks (areas of high wet deposition) over the mountain regions of the MC, particularly in western Borneo, with peak deposition occurring in the mountain rainforest of Gunung Niut Penrisen Nature Reserve. For later MJO phases, wet deposition (and hence smoke cloud-precipitation interaction) spreads much further into the oceans and into the summer monsoonal trough. Indeed, the existence of high terrain on Borneo and Sumatra appears to enhance rising and sinking motions associated with the MJO, which exhibit quasi-stationary features (Wu et al., 2009). Interestingly, the peak in wet deposition east of the Philippines, in the heart of the summer monsoonal trough, corresponds to a recent observation of increased thunderstorm flash rate and AOD from local volcanic activity (Yuan et al., 2011). Our finding not only suggests a mechanism for smoke transport into this same region, but cautiously warns us that there are also different meteorological states at work between the different MJO phases.

\section{Results - Meteorological context d: higher frequency wave phenomena}

After the MJO we move away from large scale features and next look at individual higher frequency events such as Equatorial Kelvin and Rossby Waves. Given our use of 9 day fire averaging and the frequency of the dominant Kelvin and Rossby models, it is difficult at the moment to relate the rainfall in the convectively coupled waves to fire counts. However, some properties of these waves may be of interest. For example, Kikuchi and Wang (2010) show that Kelvin waves 

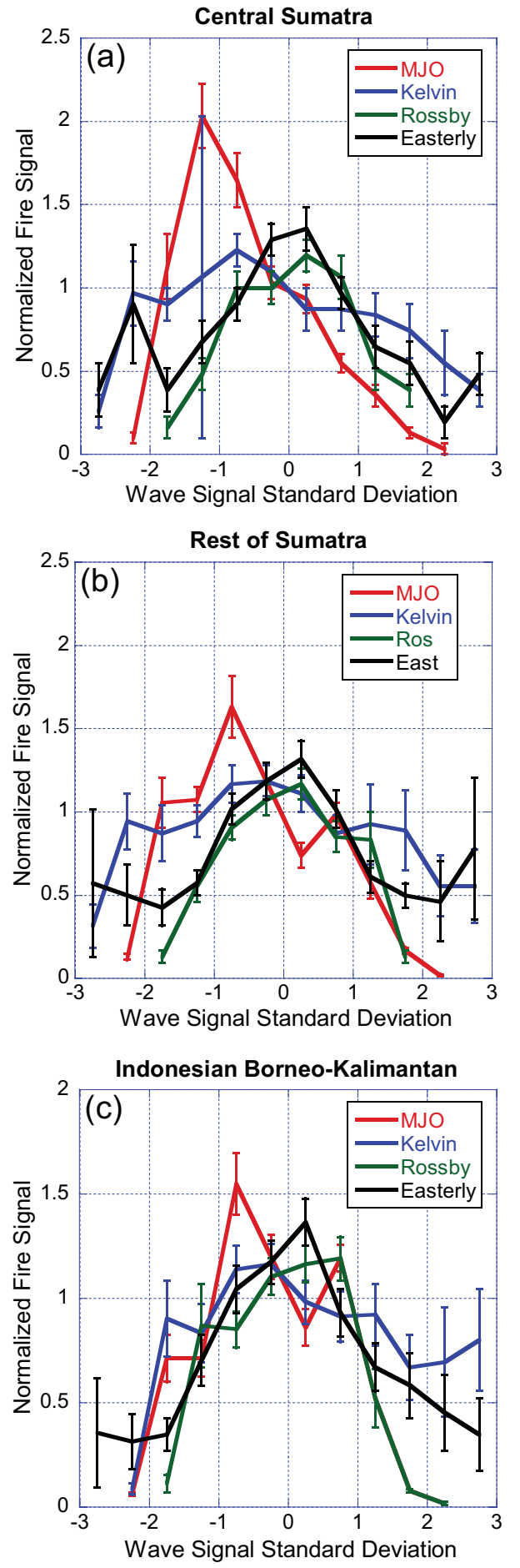

Fig. 11. Normalized fire signal as a function of normalized precipitation anomalies associated with the tropical disturbances (in units of relative standard deviation) for June-November burning season. (a) Central Sumatra. (b) Rest of Sumatra. (c) Indonesian Borneo. are usually observed ahead of MJO convection. This could explain why there is relatively less fire activity during the very early MJO phases (i.e., phases 1 and 2), before the convection reaches the $\mathrm{MC}$, compared with after the convection passes. Another feature is the enhancement of the amplitude of Kelvin waves inside the MJO "convective envelope" (Roundy, 2008).

To identify the signal of meteorological phenomena at different time scales, we examined spectral output from a test line of $106^{\circ} \mathrm{E}$ from -5 to $5^{\circ} \mathrm{N}$. This line is largely over water between Sumatra and Borneo. Based on spectral filtering of the TRMM precipitation we derived filtered precipitation anomalies in several equatorial modes (Wheeler and Kiladis, 1999): eastward propagating Kelvin Waves (with dominant periods of about 7 days) westward propagating Rossby Waves (10-20 days), easterly waves (3-9) and the eastward propagating MJO (30-60 days). Precipitation anomalies for each of these waves were then normalized by the study period mean standard deviations to yield an index. Given the proximity of this test line to the fire dominant islands of Sumatra and Borneo, we present results for Central Sumatra, Rest of Sumatra (dominated by the south) and Indonesian BorneoKalimantan in Fig. 11.

Given the findings of Sect. 6, by this method we would expect a strong MJO signal, particularly for central Sumatra. Fire activity peaks there for negative precipitation anomalies up to +1.5 standard deviation events. For both very strong wet or dry phases, the fire signal drops significantly. This may be because strong wet and dry phases are coupled. As fuel requires a drying time before it can be ignited, a strong dry phase following right after a strong wet phase may not produce the required drying for fire ignition. Although not as strong, the rest of Sumatra and Kalimantan show a similar pattern. The MJO also frequently spawns Kelvin waves and hence they show similar patterns for central Sumatra. But the signal is weak, in part due to their short period relative to our 9 day fire average.

Like the overarching MJO, Rossby and easterly waves have active wet and dry components. Hence, one might initially hypothesize similar behavior to the MJO with increased fire activity in dry phases. However, because these waves are ultimately one coupled system and of much shorter period, strong dry phases are also coupled to strong wet phases at relatively high frequency. Consequently, fire activity was found to center at zero anomaly and be a minimum for precipitation anomalies of high absolute value. The fuel drying that mediates the relationship between precipitation and fire activity acts as a buffer, so that strong dry phases of high-frequency waves do not yield enhanced fire activity. 

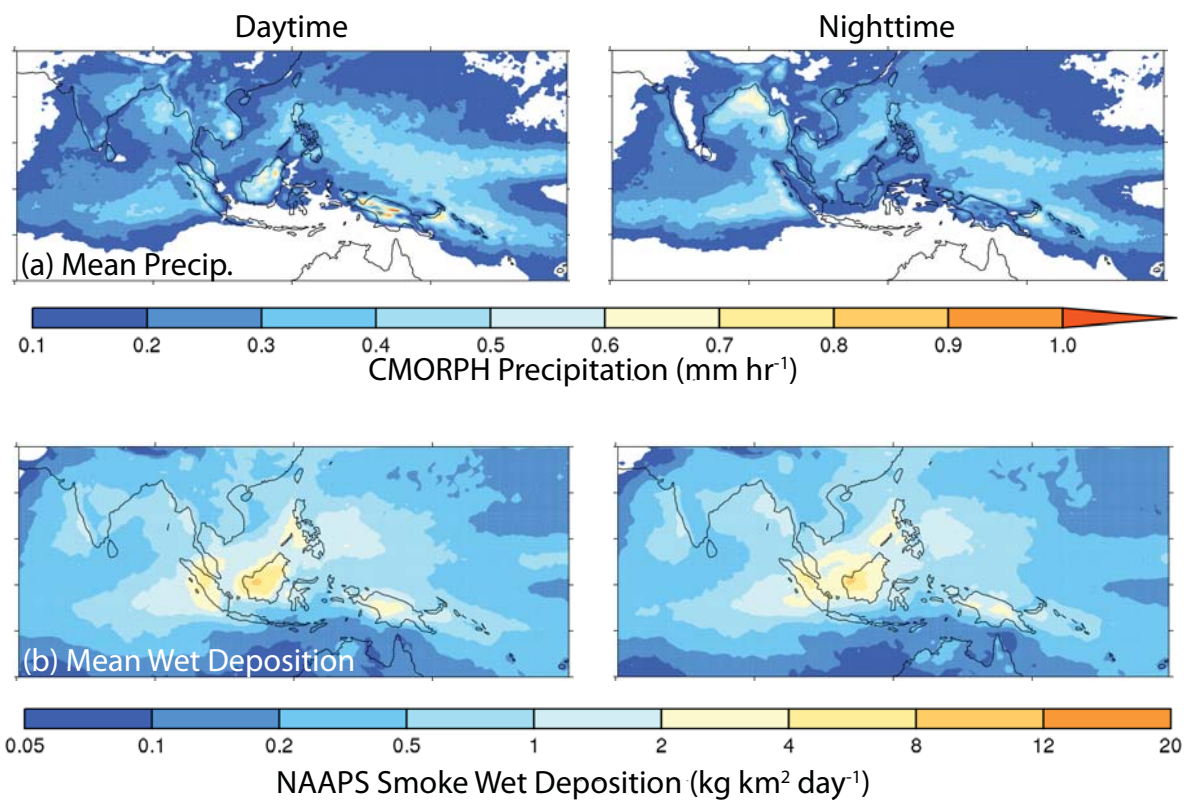

Fig. 12. Diurnal statistics of daytime and nighttime (a) CMORPH precipitation and (b) NAAPS smoke wet deposition.

\section{Diurnal variability and smoke-convection interactions}

The finest scale to be examined here is the diurnal cycle. As discussed earlier and as presented in Table 1, observed fire patterns have a strong diurnal cycle which peaks in the mid to late afternoon and subsides at night to a minimum in the morning. This is demonstrated in Fig. 12, where we present diurnal precipitation and smoke wet deposition maps for the MC. Convection has a diurnal cycle as well. Over land, convection peaks in the late afternoon (15:00-18:00 LST) with a maximum in ground heating. Over the tropical ocean however, convection peaks at 03:00-06:00 LST (e.g. see review by Yang and Smith, 2006). The reason for the nighttime precipitation maximum over the ocean is still not fully understood. One hypothesis is that cloud top cooling results in radiative instability. It might be related to the life cycle of marine mesoscale convective systems that initiate during afternoon and peak $12 \mathrm{~h}$ later (Chen and Houze, 1997). Likely there are a multitude of processes at work. Studies discussing the nature of diurnal precipitation in the South China Sea and MC include Yang and Smith (2006), Yang et al. (2008) and Li et al. (2010), and Johnson (2011)

The diurnal cycle of convection dictates the nature of smoke-cloud-precipitation interaction, with hence wet deposition over land and ocean tracking the cycles of convection. Given fire activity peaks at $\sim 15: 00 \mathrm{LST}$, there is potential for smoke to be immediately entrained into nearby isolated convection. This situation probably occurs most frequently in Sumatra where smoke production is very close to the mountains. Given the previously shown figures of regional precipitation, smoke cloud-precipitation interaction is more likely to be dominant over southwestern Kalimantan-Indonesian Borneo, and Sarawak-Malaysia Borneo, or perhaps convection on the Malay Peninsula- all associated with orographic convection. With prevailing winds such smoke can be aged for up to $24 \mathrm{~h}$ before interacting with clouds there. For example, in western or southern Kalimantan, precipitation reaches a maximum along the mountain range, with maximum wet deposition occurring in a gap in the mountains. In the afternoon, the strong sea breeze likely enhances convection ( $\mathrm{Li}$ et al., 2010); the late afternoon precipitation increases after the onset of the SCS summer monsoon over the northern SCS. Hence, in this region there may be some decoupling of drought in the burning area and the prevalence of sea-breeze thunderstorms along the western coast of Borneo. Indeed, from Table 2, whereas southern and western Kalimantan lose $70 \%$ and $50 \%$ of their summer time precipitation in an El Nino year, respectively, Sarawak only has a $15 \%$ deficit. The Malay Peninsula shows no climatological difference. Given the high concentration of radiosonde observations in the region (supported by the Malaysia Meteorological Service), central Sumatra, Sarawak, and the Malay Peninsula seem optimal for controlled studies of smoke convection interaction.

Smoke not removed by convective activity over land then moves into the SCS or Indian Ocean and is subject to nighttime scavenging in the West Sumatran Low, the SCS, or further on in the monsoonal trough. Graf et al., (2009) suggested that in regions where smoke resulted in land precipitation suppression there would be less wet scavenging. Hence, such smoke would then be available for longer range transport and perhaps would enhance precipitation over the water. 
With a peak in precipitation over Sarawak (in western Borneo) in the late afternoon, estimates of smoke exiting Borneo are likely to be uncertain. Hence, such smoke-cloudprecipitation interaction is more difficult to observe in the nighttime over ocean precipitation maximum; the over water morning precipitation maximum is almost $18 \mathrm{~h}$ from the last AOD capable satellite overpass. It is nonetheless important since we suspect that half of the smoke is scavenged over oceans, and Graf et al., (2009)'s hypotheses should be tested. In regards to ENSO, the early morning ocean rainfall peak is much stronger in La Nina years ( $\mathrm{Li}$ et al., 2010). Hence, higher smoke production in El Nino years likely results in more long range transport and a higher probability of smoke reaching the summer monsoonal trough.

\section{Results - the tropical cyclone inflow and subsidence regimes}

One last area that warrants special attention in our analyses is the relationship of tropical cyclones (TCs) with weather in the MC. While TCs do not propagate across the equatorial MC it appears that they nevertheless affect precipitation and hence burning in the region. While conducting this study, and repeatedly examining daily precipitation and fire maps, we noticed increased severe fire events in Borneo and Sumatra when TCs propagated across the northern SCS. This observation led to questions about whether this perceived relationship could be quantified, and whether some theories on this relationship could be developed.

A possible answer to these questions was proposed to us by operational forecasters at the Joint Typhoon Warning Center (JTWC) at Pearl Harbor Hawaii. They pointed out that very often well developed TCs near the equator produces enhanced southwesterly wind flow at the surface, and southerly outflow aloft that moves equatorward and enhances subsidence and thus dryness over the MC. These upper level outflows can be seen in hand analyses with the benefit of geostationary data, but are not always present in model data. A good composite study of equatorial outflow interaction with a Southern Hemisphere anticyclone is included in Chen and Gray (1985). Similarly, the link between TC activity in SCS and fire activity in the MC has been noticed by in situ forecasters with the Malaysian Meteorological Department. In recent discussions with these forecasters, it was brought to light that they use the presence of a TC in the SCS to forecast both decreased precipitation and lower air quality in the Malay Peninsula. Again, while this is a forecast tool, we have not seen this documented in the peer reviewed literature.

Based on the JTWC best tracks in the Automated Tropical Cyclone Forecasting (ATCF) system (Sampson and Schrader, 2000) and the analysis of Goh and Chan (2010), there are $~ 5-15$ named TCs in the SCS each year, evenly divided between those entering and forming inside the SCS. Typically, the strongest storms in the SCS form out in the
Pacific Ocean and pass over Luzon, Philippines where they weaken and possibly regain strength in the SCS. Most of these TCs form in the monsoon trough.

A good example of burning activity-TC coupling was found for late September, early October 2007, when TC Lekima was active in the SCS 29 September-3 October 2007. Lekima was the last of a series of three storms passing through the SCS in rapid succession (Nari, Francisco, then Lekima). Krosa followed Lekima, but eventually veered north towards Taiwan and away from the SCS. With winds varying between 25 and $35 \mathrm{~m} \mathrm{~s}^{-1}$, Lekima strengthened into a typhoon on 2 October and made landfall in Vietnam on the 3rd. A synopsis of the environment can be found in Fig. 13a where we present CMORPH $24 \mathrm{~h}$ precipitation on top of the $12 Z$ IR MTSAT image. Also included is that day's MODIS fire counts (red = Aqua; blue $=$ Terra) and the NOGAPS $12 \mathrm{Z}$ $850 \mathrm{hPa}$ winds. For describing the upper level environment we show the $150 \mathrm{hPa}$ NOGAPS winds and $500 \mathrm{hPa}$ Omega field. From Fig. 13, we can see significant burning activity over southern Kalimantan. In fact, this was the peak burning day for that season. The impact of clouds on fire detection is also visible with a thick high cloud layer bisecting Borneo. No detected precipitation fell on Borneo that day. On Sumatra, however, clouds and precipitation is present over much of the northern half of the island. Only a few fires were observed in southern Sumatra and then only from MODIS Terra.

Looking at the large scale meteorology, we can see Lekima in the SCS and the initial stages of Krosa to the east. Precipitation is present all along the $850 \mathrm{hPa}$ inflow arm into Lekima. This inflow is in phase with the seasonal southwesterly monsoonal winds. Winds are also accelerated to the south and east of this arm, enhancing smoke transport into the Sulu Sea. NOGAPS omega anti-correlates reasonably well with CMORPH precipitation. At $150 \mathrm{hPa}$ we see the anti-cyclonic winds out of the TC region. Compared to the NOGAPS and NCAR climatologies, these wind speeds are a factor of 2 higher than climatology. Over much of the MC winds are converging, leading to large scale subsidence - perhaps in turn inhibiting precipitation and clouds and hence enhancing the fire signal. From this example, we can see potentially how TCs can both enhance or retard the fire signal. In TC outflow regions with upper level convergence, large scale subsidence can impede precipitation and or cloud cover, thus providing more favorable conditions for fire or fire observability. Conversely, if in the TC inflow arm, precipitation and cloud cover can be enhanced.

While the above scenario seems plausible, it is difficult to verify objectively at this time. Like the MJO analysis, we generated statistics on fire prevalence versus SCS TC activity for the 2003-2009 fire seasons. During this period, there was a total of 113 tropical cyclone days (tropical storm strength or greater) from 54 storms developing or moving into a SCS box defined as $5-20^{\circ} \mathrm{N}$ and $110-120^{\circ} \mathrm{E}$. In general, fire prevalence was higher when TCs were in our sample 

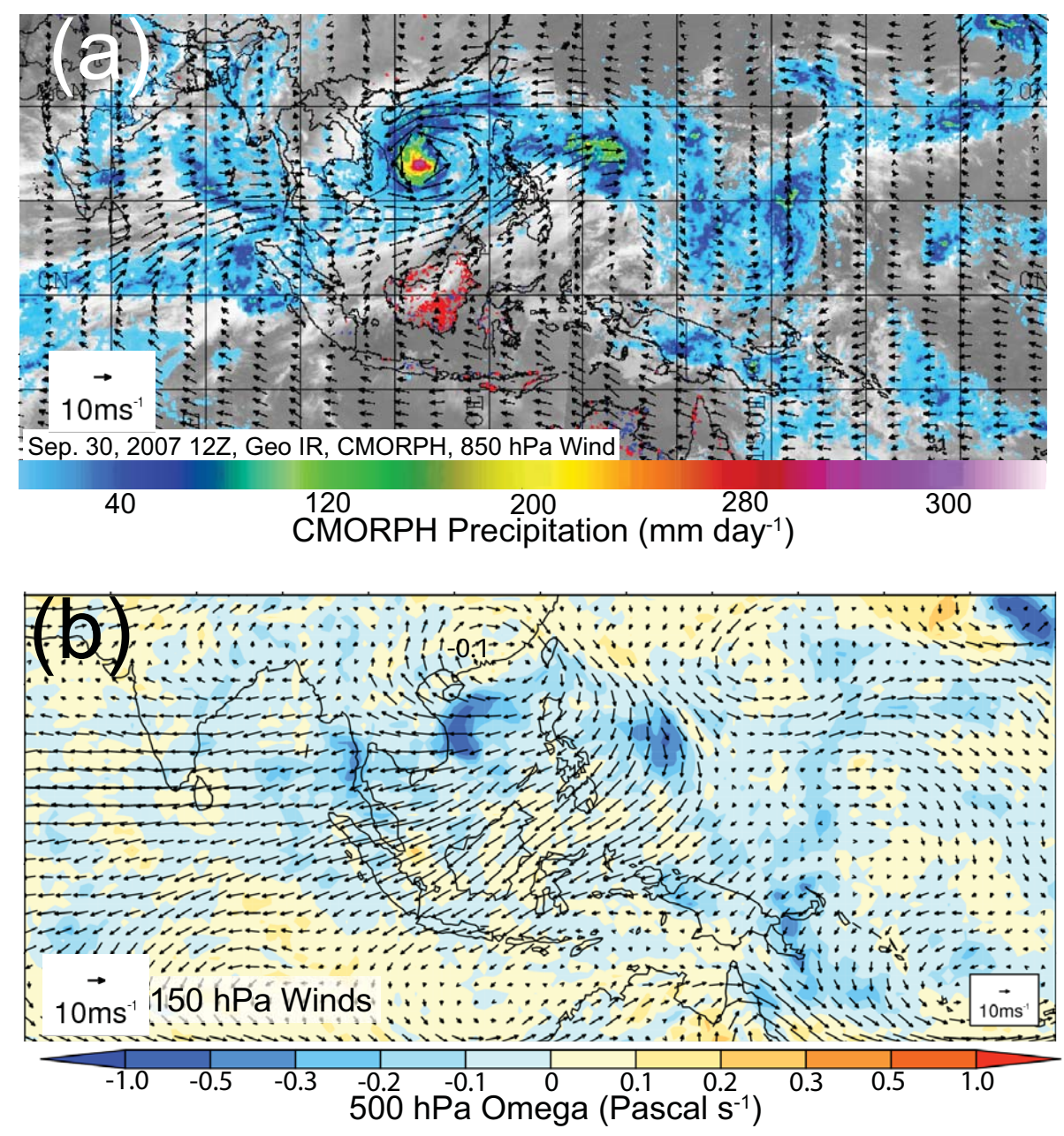

Fig. 13. (a) $24 \mathrm{~h}$ CMORPH precipitation, NOGAPS $850 \mathrm{hPa}$ winds MODIS Fire counts (blue = terra, red = aqua) overlaid on the 12Z MTSAT IR image for 30 September, 2007. (b) NOGAPS $150 \mathrm{hPA}$ winds overlaid $500 \mathrm{hPa}$ omega fields for the same period.

box. Indonesian Kalimantan has by far the largest signal, with $153 \pm 21$ (average \pm standard error) observed fire counts per day during TC periods versus $111 \pm 5$ for non TC days during the core June-November time period. This was totally dominated by the signal from our Southern Kalimantan sector (106 \pm 18 versus $70 \pm 4$ ). Malaysian Borneo however, showed no signal ( $12 \pm 2$ versus $11 \pm 1$ fire counts per day) but again there may be regulatory or diurnal cycle/observability factors in play. Sumatra also showed no signal although the southern portion had a slight positive tendency $(66 \pm 10$ versus $53 \pm 3$ for TC and non TC). The remaining islands had $78 \pm 7$ detections per day for TC days versus $67 \pm 2$ non TC days. Stronger storms appeared to have stronger associated fire activity, although the sample is limited since only 12 storms greater than category $3\left(114 \mathrm{kt}\right.$ or $\left.210 \mathrm{~km} \mathrm{~h}^{-1}\right)$ occurred during our study period.

While the above numbers seem compelling, we must still be mindful of other meteorological confounders. In contrast with the long term analysis of Goh and Chan (2010) which suggests weaker SCS TC activity in El Nino years, during our study period, we found the 2006 and 2009 El Nino years to have above normal TC counts and strengths. Further, Chu (2004) suggest there is also a tendency for tropical cyclones to form closer to the equator during El Nino years, and this meridional shift is clear in peak and late season. The number of TC days in our study area is also strongly correlated with MJO phase, at 15, 6, 8, 28, 21, 17, 4, and 14 for phases $1-8$ respectively. Thus, a portion of the TC signal is collinear with our MJO correlations. This is not wholly surprising as many long noted the relationship between cyclogenesis and the MJO (e.g., Liebmann et al., 1994; Maloney and Hartman, 2001). But it does perhaps explain some of the counterintuitive behavior seen in Fig. 9. Even though the MJO progresses from west to east, we see the fire impact of the MJO for central Sumatra later than Indonesian BorneoKalimantan. This may very well be influenced by TCs in the SCS. With peak TC activity in MJO phases 4 and 5, we may have enhanced drying over Borneo from TC outflow, with 
central to northern Sumatra being influenced by convection associated with TC inflow. Finally, again we must consider the observability issue. TC outflow and its relation to the MJO may not in fact influence fires, but rather the cirrus level which inhibits fire observations.

The above positive and negative evidence points to the difficulty in interpreting the meteorology of MC. Is it the TC enhancing upper level winds and subsequent large scale subsidence in the region, or is the presence of TCs in the SCS indicative of a large scale shift in the MJO, cyclogenesis, the steering flow, or even cirrus cloud cover. Chen and Gray (1985) cite evidence of an equatorial outflow jet enhancing TC development, while modeling efforts (Shi et al., 1990; Titley and Elsberry, 2000) and operational forecasters commonly see outflow as a result of TC development.

\section{Discussion: implications of findings for prognostic potential}

The impact of biomass burning emissions in the $\mathrm{MC}$ on air quality and potentially climate is of great concern to countries in the region. During scientific meetings, the potential for seasonal fire forecasting frequently arises. Of course, forecast system developers are at a disadvantage here given the inherently anthropogenic nature of burning in the MC. Given that the MC does not have significant natural fire ecology and that virtually all fires in the MC are anthropogenic in origin, the observed fire signal is a result of societal, economic and land management pressures coupled with meteorological factors. This paper is dedicated to the meteorological part, but human factors provide the underlying and difficult to apply forcing. If better land management practices prevail over the next few years, the efficacy of any parametric model derived from data over the last decades could be rather short lived. But even so, there is a need for rules of thumb to help scientists in the ongoing 7SEAS and imminent SEAC4RS campaigns as well as aid air quality forecasters.

Based on Field and Shen (2009) and extended and verified by this research, the use of an El Nino index forecast or, on shorter time scales, a running 90 day precipitation anomaly from either gauge or satellite based precipitation products appears to be a rather robust indicator of the amplitude of burning in the dominant southern Kalimantan and southern Sumatran regions - if it is interpreted as a tipping point. But, outside of these regions, this relationship appears to weaken, particularly in field agriculture regions. Nevertheless, this relationship will allow scientists to prepare for the largest burning seasons.

In addition to the seasonal forecast, we can see that climate grade statistics of higher frequency phenomenon such as the $\mathrm{MJO}$ are also rather robust at even the weather scale. Indeed, a keen observer of standard MJO Hoffmueller diagrams will also likely attain skillful forecasts out to one or two weeks. But there is solid potential for the use of NWP systems or development of a more sophisticated parametric model. Vitart and Moleti (2010) recently demonstrated prediction skill of subseasonal features out to four weeks using the ECMWF forecast model.

Higher resolution wave phenomena are more problematic in that their impact is not well represented by the fire data used in this study. But, the Kelvin wave signal is partially incorporated into the $\mathrm{MJO}$, and clearly lower amplitude precipitation anomalies correspond to higher fire prevalence for other short period phenomena. TCs in the SCS, however, appear to have a strong enough signal to overcome our fire data averaging. While this indicator appears to have skill, and apparently has been used by regional forecasters, this signal is in part collinear with the MJO. Further research is required.

Finally, our findings have implications for climate simulations. The complexity of the meteorology-fire system, with its dependence on such features as ENSO, the MJO, diurnal precipitation cycles and potentially TCs, sets a fairly high level of difficulty for climate models which sometimes have difficulty representing these key meteorological features (e.g., Latif, et al., 1998; Achutarao and Sperber, 2006; Aldrian et al., 2007; Xian et al., 2009; Stephens et al., 2010). The strongest observed fire events are those with clear coupling to both interannual AND mesoscale phenomenon. Indeed, replicating ENSO and the MJO in a global climate model is a challenge (van Oldenborgh et al., 2005; Innes and Slingo, 2006), and mesoscale simulations of MJO propagation across the MC are in their infancy. In addition, modeling diurnal precipitation cycles is also challenging. Even so, higher resolution modeling with explicit microphysics is generating hypotheses worthy of further study (e.g., Graf et al., 2009).

\section{Summary and conclusions}

The purpose of this paper is to examine the MODIS fire record for the last decade and try to find influences of various meteorological phenomena on burning in the Maritime Continent (MC). While statistical studies have been conducted centered on the dominant southern Kalimantan and southern Sumatran fire signal from the massive 1997 and 2006 El Nino events, we examined fire activity in the entire MC from 2003-2009 (when both Terra and Aqua MODIS data are available) relative to ENSO, the Indian Ocean Dipole, El Nino Modoki, monsoonal cycle, MJO, tropical cyclones, tropical waves and diurnal cycles. The fire activity was combined with satellite precipitation estimates and a reanalysis of the NAAPS aerosol model with aerosol optical depth data assimilation and satellite specified wet scavenging. Because of the complexity of the system, we provide in Appendix A brief descriptions of how these key phenomenon manifest themselves for representative years in the study period. In our analysis we found the following key findings. 
1. Each island or even sub-region on each island has different sensitivities to meteorological scale, likely through the relative amount of peatland conversion, mountain deforestation, oil palm maintenance and crop residue burning. Burning activity on the islands of Borneo and Sulawesi respond more strongly to ENSO and ITCZ migration than other regions where burning is more consistent. However, other regions which are nearly all crop residue burning, such as Java, still have a slight ENSO signal which may be in part related to regional observability. Weather that promotes drying and fire also results in less regional precipitation and an eastward shift in the summer monsoonal trough. Hence, not only is there more smoke production during El Nino years, but smoke has longer range transport.

2. Regarding other interseasonal behavior, strong spikes in the IOD clearly appear at the end of significant El Nino burning seasons. However, at this time we can not ascertain the exact nature of the relationship between fire in the MC and the IOD. Similarly, fire activity appears to be enhanced in El Nino Modoki years. The mechanism is generally unstudied.

3. The migration of the ITCZ between the summer (AprilNovember) and winter (November-April) defines the bulk of the seasonal burning. However, as the monsoon arrives later in eastern islands of the MC, burning typically lasts longer than in the west. Even so, it appears that in El Nino years the ITCZ flips back to the MC early, producing a "dry monsoon" where burning is prolonged and/or enhanced on Borneo or Sumatra. This leads to flow reversal in the SCS and a transport pattern bringing smoke into the Indian Ocean. It needs to be recognized that these severe events have a significantly different meteorological phenomenology than more typical seasons.

4. In the wet December through May period fires still are sporadically observed throughout the MC. "Out of season burning" occurs in particular when the boreal winter ITCZ migration is at its most southernmost extent or in the spring following a large El Nino event. Burning in central Sumatra is apparent in any prolonged dry spell of a week or more. Agricultural burning in central Sumatra in wintertime 2005 was extreme.

5. If ENSO phase is the strongest indicator of total burning, the MJO often dictates when observed burning occurs in any given season. While each island has its own sensitivity, Sumatra and western Kalimantan are influenced by the phase of the MJO more than the other regions. This may be due to a combination of sensitivity to the MJO precipitation coupled with agricultural maintenance use of fire.
6. Because the MODIS orbit necessitated 9 day boxcar signal averaging, our ability to assess the impact of shorter period wave phenomena is greatly reduced. However, we found that convectively coupled Kelvin waves are largely incorporated into the MJO signal. For Rossby and Easterly waves, our rudimentary analysis suggests that increased observed fire prevalence is associated with wave quiescence - when the precipitation anomaly amplitudes are high, the fires are largely absent. Strong dry periods are usually proceeded and followed by strong wet periods. This short period may not allow enough time for fuels to dry.

7. While tropical cyclones do not propagate across the $\mathrm{MC}$, they are a common occurrence in the SCS. In hand analysis of numerous cases, we noticed a common pattern of subsidence over southern Kalimantan from upper level TC outflow, coupled with precipitation in the TC inflow regions of central and northern Sumatra. As a consequence, when TCs are in the SCS, observed fire count is enhanced in Kalimantan and suppressed in central Sumatra. Transport of smoke into the SCS or Sulu Sea may be inhibited or enhanced based on the relative position of precipitation and flow acceleration into the TC. Part of this signal may be related to MJO phases 46 , which has been shown to impact TC cyclogenesis in the region. This TC component may in part explain why burning in southern Kalimantan leads Sumatra with respect to MJO phase, even though the island of Borneo is east of Sumatra. Aspects of this mechanism apparently have been recognized by regional forecasters, although the result has not (to our knowledge) been published in the peer reviewed literature nor presented at scientific meetings.

8. The MC is well known for its diurnal patterns of precipitation maxima in the late afternoon and early morning over land and water, respectively and their associated sea breezes. Given the island specific diurnal cycle in burning activity, these high frequency phenomena likely dictate the diurnal variability in wet deposition and hence when aerosol-cloud-precipitation interaction can be observed. A region of particular note is the $1-4 \mathrm{~km}$ high mountains of Borneo where a strong sea breeze/anabatic wind cycle results in frequent thunderstorms that are not as severely modulated by ENSO as much of the surrounding region. Hence, this may be a good location to examine aerosol/cloud/precipitation interaction while controlling for ENSO induced smoke production.

9. The robust nature of some of these features (e.g., ENSO helps predict seasonal magnitude whereas MJO predicts intraseasonal timing of fire activity) leaves open the possibility of developing parametric guidance of fire and aerosol forecasting. 
10. Finally, this study demonstrates how difficult the problem is to deconvolute climate change signals in the MC. The relationship between fire emissions, and the potential effect on precipitation, as well as the observability of fire and precipitation, are all connected to the underlying meteorological forcing. The strongest observed fire events are those with clear coupling to both interannual AND mesoscale phenomenon. Uncertainty in unknowns in future land practices adds another complicating dimension. Modeling these interactions poses a significant challenge to the climate community.

\section{Appendix A}

\section{Climate versus weather: 2007 and 2009 as examples}

The conceptual models and data provided in Tables 1-3 described in the previous section demonstrate relationships between many of the meteorological scales of interest and observed biomass burning in the MC. However, by performing a bulk analysis on such factors as ENSO and MJO phase, TC presence etc., we are in danger of losing sight of our goal, which is the coupling of weather phenomena and fires. We also would like to know how to use these indicators in a prognostic model or forecast tool. To do the job properly, we should do a detailed analysis of each fire event of each year. But such an undertaking is far beyond the scope of this one study. However, we did do a brief hand analysis for each year. Key information on observed fire prevalence and meteorological indicators were derived from the data found in Figs. 4, 5, 7, and 8. Our results are synthesized in this sub section. A particular emphasis is placed on 2007 and 2009, as these years represent an ENSO neutral and positive phase without being the most extreme events. Using these years also overlaps with the pinnacle of A-train data coverage which permits subsequent studies to leverage data not included in this analysis (e.g. CloudSat, CALIOP). Figure A1 shows fire prevalence, MJO phase and strength, and TC activity in the SCS, for (Fig. A1a) 2009 and (Fig. A1b) 2007.

2009: 2009 marked a reasonably strong El Nino event. As has been well shown in previous papers and our analysis, the regional negative precipitation anomaly resulted in significantly enhanced burning, with the strongest influence on burning activity in Indonesian Kalimantan. Fire activity in central Sumatra is sporadic throughout the year, with distinct burning events in late January and February. These coincided with the recycling of the MJO from phase 8 to 1 . A minimum occurred in phases 4 and 5. During this period, the region is recovering from a strong $2008 \mathrm{La}$ Nina event resulting in the smallest fire season in the past $10 \mathrm{yr}$. ENSO passed into the positive phase in May when negative precipitation anomalies become apparent. By late May, sporadic fire activity began in Sumatra, coinciding with assigned MJO phases 6-8. This MJO event had a strong amplitude, but did not show a partic-
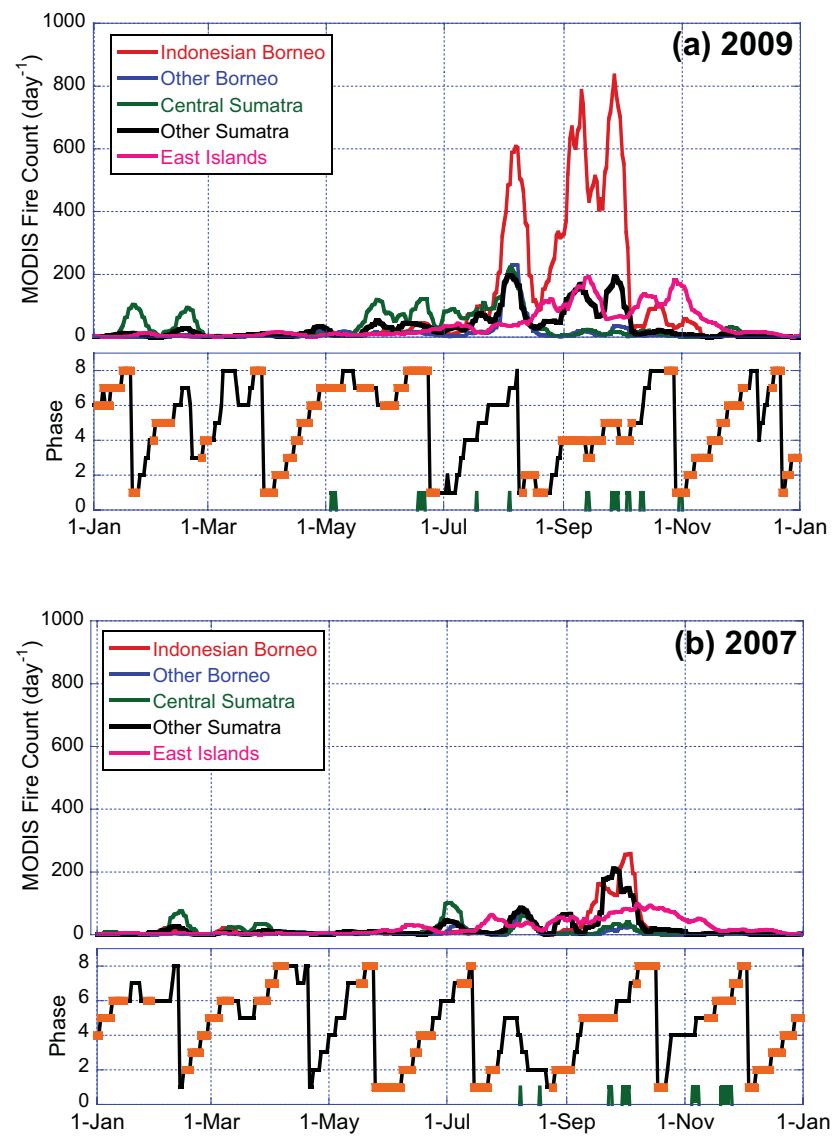

Fig. A1. Maritime continent fire counts on top of MJO phase and TC data for (a) 2009 and (b) 2007. MJO phase is highlighted orange when the MJPO amplitude is greater than 1. Active tropical cyclones in the South China Sea are indicated by a green dash.

ularly strong eastward propagation and hence was not considered an MJO event in our analysis in Sect. 6. The first large fire outbreak peaked on 7 August. In this case the increase in observed fire activity occurs along a weak amplitude eastward-propagating MJO event. Fire activity peaks for phases 6 and 7. As the MJO initiates again in the Indian Ocean and proceeds to phases 1 and 2, burning drops off dramatically. Fire ramps up again with peaks on 11 and 27 September. Fire dramatically falls off in early October in association with the end of the summer monsoonal period, although as is typical a late season burning peak in the eastern islands of Maluku, Timor, and New Guinea occurs around November $1^{s t}$. Also, 2009 had an abnormally high number of TCs in the SCS. If for this year we consider the fire season to begin in late May and continue through October, then 8 of the 9 TCs within the SCS box coincided with peaks in fire activity in Indonesian Kalimantan.

2007: Opposite to 2009 in many respects, 2007 was coming off of a very strong El Nino season and fire event in 2006 and stayed in neutral conditions for the remaining part of the year. Sporadic fires also appeared in February and March, 
although not as strong as 2009. Like 2009, the burning peak occurred in the cycling of the MJO from phase 8 to 1 . In July and August sporadic fire activity began. The first event on 1 July corresponded to a relatively strong coherent MJO event for phases 5, 6, and 7. The next set of minor events occurred in without any real MJO activity but perhaps some influence from a TC on 8 August. The only significant fire event occurs 15 September to 7 October corresponding to a moderately strong MJO cycle and phase 6-7. Two TCs in the SCS were embedded in this period. The fire season ended with the return from the summer monsoon. However, as is typical burning continues in the eastern island such as Maluku and New Guinea well into November.

We present the above details for seasons which are close to the interannual mean of fire activity. Even here we can see how climate statics can be viewed in the context of weather. Notable aspects of other years include:

2003: This was a neutral ENSO year with moderate burning. This year showed the weakest MJO relationship with fire. Even so, the strongest peak on Borneo corresponded to a weak MJO phase 4 coupled with two TCs.

2004: This El Nino enhanced burning season also showed the strongest fire activity-MJO coupling of our study period. Early season burning events in central Sumatra for 16 May and 19 June, as well as two high amplitude Indonesian Borneo-Kalimantan peaks on 21 August and 14 October were all associated with strong MJO events in phase 48 , separated by a fire minimum associated with strong MJO phases 1 through 3 . There was little burning in central Sumatra in January-March, and burning went longer than is usual in Indonesian Kalimantan and Sulawesi, interestingly associated with an early transition from the summer to winter monsoon. TC activity was the lowest of any year in our study.

2005: This moderate burning year was ENSO neutral but positive in El Nino Modoki. But January-March 2005 showed the strongest southward propagation of the winter monsoon for our study period, coupled with a very intense and slow moving MJO phases 5-8. This was also a strong El Nino Modoki period as well. These factors left central and northern Sumatra dry, resulted in the largest single burning event in central Sumatra over our entire study period.

2006: 2006 was the year had the strongest El Nino induced fire event and lowest precipitation since 1997. The highest fire peak, which covered all of Indonesian Kalimantan and southern Sumatra, coincided with a very strong and fast moving MJO event with a category 4 TC in the SCS. A very strong spike in the IOD index also occurred late in the season, but also after the majority of the fires had taken place.

2008: This was the strongest La Nina year with the highest burning season precipitation levels. There was very little fire activity, but the largest "peak" was related to MJO Phase 5 and TC activity.
Acknowledgements. We are grateful to many of our 7SEAS partners for helpful discussions, and in particular Jukka Miettinen of the National University of Singapore Center for Remote Imaging. Sensing and Processing. We are also grateful to Song Yang, NRL, for helpful discussions on diurnal precipitation in the region. This paper was supported by the NRL Base Program, NASA Interdisciplinary Science Program, and the Office of Naval Research Code 32.

Edited by: S. Kloster

\section{References}

Achutarao, K. and Sperber, K. R.: ENSO simulation in coupled ocean-atmosphere models: Are the current models better?, Clim. Dynam., 27, 1-15, 2006.

Adler, R. F., Kidd, C. , Petty, G., Morissey, M., and Goodman, H. M.: Intercomparison of global precipitation products: The Third Precipitation Intercomparison Project (PIP-3), B. Am. Meteorol. Soc., 82, 1377-1396, 2001.

Aldrian, E., Dumenil, G. L., and Widodo, F. H.: Seasonal variability of Indonesian rainfall in ECHAM4 simulations and in the reanalyses: the role of ENSO, Theor. Appl. Climatol,, 87, 41-59, doi:10.1007/s00704-006-0218-8, 2007.

Aldrian, E. and Djamil, Y. S.: Spatio-temporal climate change of rainfall in Eastern Java Indonesia, Int. J. Climatol., 28, 435-448, 2008.

Andreae, M. O., Rosenfeld, D., Artaxo, P., Costa, A. A., Frank, G. P., Longo, K. M., and Silva-Dias, M. A. F.: Smoking rain clouds over the Amazon, Science, 303, 1337-1342, 2004.

Ashok, K., Behera, S. K., Rao, S. A. , Weng, H., and Yamagata, T.: El Ninõ Modoki and its possible teleconnection, J. Geophys. Res., 112, C11007, doi:10.1029/2006JC003798, 2007.

Annamalai, H.: Moist dynamical linkages between the equatorial Indian Ocean and the South Asian monsoon trough, J. Atmos. Sci., 67, 589-610, 2010.

Annamalai, H., Kida, S., and Hafner, J.: Potential impact of the tropical Indian Ocean-Indonesian seas on El Nino Characteristics, J. Climate, 23, 3933-3952, 2010.

Balasubramanian, R., Qian, W.-B., Decesari, S., Facchini, M. C., and Fuzzi S.: Comprehensive characterization of $\mathrm{PM}_{2.5}$ aerosols in Singapore, J. Geophys. Res., 108, 4523, doi:10.1029/2002JD002517, 2003.

Beegum, S. N., Moorthy, K. K., Babu, S. S., Reddy, R. R., and Gopal, K. R.: Large scale modulation of spectral aerosol optical depths by atmospheric planetary waves, Geophys. Res. Lett., 36, L03810, doi:10.1029/2008GL036509, 2009.

Cai, W., van Rensch, P., Cowan, T., and Hendon, H. H.: Teleconnection Pathways of ENSO and the IOD and the Mechanisms for Impacts on Australian Rainfall, J. Climate, 24, 6035-6053, doi:10.1175/2011JCLI4149.1, 2011.

Chang, C.-P., Wang, Z., Mcbride, J., and Liu, C.-H.: Annual cycle of Southeast Asia-Maritime Continent rainfall and asymmetric monsoon transition, J. Clim., 18, 287-301, 2005.

Chang, C.-P., Ding, Y., Lau, N.-C., Johnson, R. H., Wang, B., Yasunari, T. (Eds.): The Global Monsoon System: Research and Forecast, second ed. World, Sci Pub., Singapore, 2011.

Chang, D. and Song, Y.: Estimates of biomass burning emissions in tropical Asia based on satellite-derived data, Atmos. Chem. 
Phys., 10, 2335-2351, doi:10.5194/acp-10-2335-2010, 2010.

Chen, L. S. and Gray, W. M.: Global view of the upper level outflow pattern associated with tropical cyclone intensity changes during FGGE. Dept. of Atmos. Sci. Paper No. 392, Colorado State University, Ft. Collins, CO, USA, 126 pp., 1985.

Chen, S. and Houze Jr., R. A.: Diurnal variation of deep convective systems over the tropical Pacific warm Pool, Q. J. Roy. Meteorol. Soc., 123, 357-388, 1997.

Chu, P.-S.: ENSO and tropical cyclone activity. Hurricanes and Typhoons: Past, Present and Potential, edited by: Murnane, R. J. and Liu, K. B., Columbia University Press, New York, NY, USA, 297-332, 2004.

Csiszar, I., Denis, L., Giglio, L., Justice, C. O., and Hewson, J.: Global fire activity from two years of MODIS data, Int. J. Wildland Fire, 14, 117-130, 297-332, 2005.

Dai, A.: Precipitation characteristics in eighteen coupled climate models, J. Climate, 19, 4605-4630, 2006.

Davison, P. S., Roberts, D. L., Arnold, R. T., and Colvile, R. N.: Estimating the direct radiative forcing due to haze from the 1997 forest fires in Indonesia, J. Geophys. Res., 109, D10207, doi:10.1029/2003JD004264, 2004.

Dinku, T., Chidzambwa, S., Ceccato, P., Connor, S. J., and Rpoelewski, C. F.: Validation of high resolution satellite rainfall products over complex terrain, Int. J. Remote Sens., 29, 40494110, 2008.

Dommenget, D.: An objective analysis of the observed spatial structure of the tropical Indian Ocean SST variability, Clim. Dynam., 36, 2129-2145, doi:10.1007/s00382-010-0787-1, 2011.

Ebert, E. E., Janowiak, J. E., and Kidd, C.: Comparison of nearreal-time precipitation estimates from satellite observations and numerical models, B. Am. Meteorol. Soc., 88, 47-64, 2007.

Field, R. D. and Shen, S. S. P.: Predictability of carbon emissions from biomass burning in Indonesia, J. Geophys. Res., 113, G04024, doi:10.1029/2008JG000694, 2008.

Field, R. D., van der Werf, G. R., and Shen S. S. P.: Human amplification of drought-induced biomass burning in Indonesia since 1960, Naure Geosci., 2, 185-188, 2009.

Feingold, G., Remer, L. A., Ramaprasad, J., and Kaufman, Y. J.: Analysis of smoke impact on clouds in Brazilian biomass burning regions: An extension of Twomey's approach, J. Geophys. Res., 106, 22907-22922, doi:10.1029/2001JD000732, 2001.

Fuller, D. O. and Murphy, K.: The enso-fire dynamic in insular Southeast Asia, Climate Change, 74, 435-455, doi:10.1007/s10584-006-0432-5, 2006.

Giglio, L.: Characterization of the tropical diurnal fire cycle using VIRS and MODIS observations, Remote Sens. Environ., 108, 407-421, 2007.

Giglio, L., Csiszar, I., and Justice, C. O.: Global distribution and seasonality of active fires as observed with the Terra and Aqua MODIS sensors, J. Geophys. Res. - Biogeosci., 111, G02016, doi:10.1029/2005JG000142, 2006.

Giglio, L., Descloitres, J., Justice, C. O., and Kaufman, Y. J.: An enhanced contextual fire detection algorithm for MODIS, Remote Sens. Environ., 87, 273-282, 2003.

Goh, A. Z.-C. and Chan, J. C. L.: Internannual and interdecadal variation of tropicsl cyclone activity in the South China Sea, Intern. J. Clim., 30, 827-843, 2010.

Graf, H.-F., Yang, J., and Wagner, T. M.: Aerosol effects on clouds and precipitation during the 1997 smoke episode in Indonesia,
Atmos. Chem. Phys., 9, 743-756, doi:10.5194/acp-9-743-2009, 2009.

Hamid, E. Y., Kawasakim, Z.-I., and Mardiana, T.: Impact of the 1998-1998 El Nino event on lighting activity over Indonesia, Geophys. Res. Lett., 28, 147-150, 2001.

Hansen, M. C., Stehman, S. V., Potapov, P. V., Loveland, T. R., Townshend, J. R. G., DeFries, R. S., Pittman, K. W., Arunarwati, B., Stolle, F., Steininger, M. K., Carroll, M., and DiMiceli, C: Humid tropical forest clearing from 2000 to 2005 quantified by using multitemporal and multiresolution remotely sensed data, Proc. Natl. Acad. Sci. USA, 105, 9439-9444, 2008.

Hawbaker, T. J., Radeloff, V. C., Syphard, A. D., Zhu, Z., and Stewart, S. I.: Detection rates of the MODIS active fire product in the United States, Remote Sens. Environ., 112, 2656-2664, 2008.

Hogan, T. F. and Rosmond, T. E.: The description of the Navy Operational Global Atmospheric Prediction Systems spectral forecast model, Mon. Weather Rev., 119, 1786-1815, 1991.

Hong, C. C., Lu, M. M., and Kanamitsu, M.: Temporal and spatial characteristics of positive and negative Indian Ocean dipole with and without ENSO, J. Geophys. Res., 113, D08107, doi:10.1029/2007JD009151, 2008.

Hergaualch, K. and Verchot, L. V.: Stocks and fluxes of carbon associated with land use change in Southeast Asian tropical peatlands: A review, Global Biogeochem. Cy., 25, GB2001, doi:10.1029/2009GB00371, 2011.

Hyer, E. J. and Chew, B. N.: Aerosol transport model evaluation of an extreme smoke episode in Southeast Asia, Atmos. Environ., 44, 1422-1427, 2010.

Hyer, E. J. and Reid, J. S.: Baseline uncertainties in biomass burning emission models resulting from spatial error in satellite active fire location data, Geophys. Res. Lett., 36, L05802, doi:10.1029/2008GL036767, 2009.

Hyer, E. J., Reid, J. S., and Zhang, J.: An over-land aerosol optical depth data set for data assimilation by filtering, correction, and aggregation of MODIS Collection 5 optical depth retrievals, Atmos. Meas. Tech. 4, 379-408, doi:10.5194/amt-4-379-2011, 2011.

Hyer, E. J., Reid, J. S., Schmidt, C., Giglio, L., Hoffman, J., Different views of fire activity over Indonesia and Malaysia from polar and geostationary satellite observations, Atmos. Res., submitted, 2012.

Huffman, G. J., Adler, R. F., Bolvin, D. T. Gu, G. Nelkin, E. J., Bowman, K. P., Hong, Y., Stocker, E. F., and Wolff, D. B.: The TRMM Multi-satellite precipitation analysis: Quasi-global, multi combined-sensor precipitation estimates at fine scale, J. Hydrometeorol., 8, 38-55, 2007.

Huffman, G. J., Adler, R. F., Bolvin, D. T., and Gu, G. J.: Improving the global precipitation record: GPCP Version 2.1, Geophys. Res. Lett., 36, L17808, doi:10.1029/2009GL040000, 2009.

Janowiak, J. E., Kousky, V. E., and Joyce R. J.: Diurnal cycle of precipitation determined from the CMORPH high spatial and temporal resolution global precipitation analyses. J. Geophys. Res., 110, D23105, doi:10.1029/2005JD006156, 2005.

Innes, P. M. and Slingo, J. M: The interaction of the Madden-Julian Oscillation with the Maritime Continent in a GCM, Q. J. Roy. Meteorol. Soc., 132, 1645-1667, 2006.

Johnson, R. H.: Diurnal cycle of monsoon convection, In The Global Monsoon System, edited by: Chang, C. P., Ding, Y., Lau, N.-C., Johnson, R. H., Wang, B., and Yasunari, T., World Scien- 
tific Press, New Jersey, USA, 257-276, 2011.

Johnson, E. A. and Miyanishi, K.: Forest fires: Behavior and Ecological Effects, Academic Press, San Diego, CA, USA, 585 pp., 2001.

Joyce, R. J., Janowiak, J. E., Arkin, P. A., and Xie, P.: CMORPH: A method that produces global precipitation estimates from passive microwave and infrared data at high spatial and temporal resolution, J. Hydrometeorol., 5, 487-503, 2004.

Jiang, J. H., Livesey, N. J., Su, H., Neary, L., McConnell, J. C., and Richards, N. A. D.: Connecting surface emissions, convective uplifting, and long?range transport of carbon monoxide in the upper troposphere: New observations from the Aura Microwave Limb Sounder, Geophys. Res. Lett., 34, L18812, doi:10.1029/2007GL030638, 2007.

Jiang, J. H., Su, H., Schoeberl, M. R., Massie, S. T., Colarco, P., Platnick, S., and Livesey N. J.: Clean and polluted clouds: Relationships among pollution, ice clouds, and precipitation in South America, Geophys. Res. Lett., 35, L14804, doi:10.1029/2008GL034631, 2008.

Justice, C. O., Giglio, L. Korontzi, S., Owens, J., Morisette, J. T., Roy, D., Descloitres, J., Alleaume, S., Petitcolin, F., and Kaufman Y. J.: The MODIS fire products, Remote Sens. Environ., 83, 244-262, 2002.

Kalnay., E., Kanamitsu, M, Kistler, R., Collins, W., Deaven, D., Gandin, L, Iredell, M., Saha, S., White, G., Woollenk, J., Zhu, Y., Chelliah, M., Ebisuzaki, W., Higgins, W., Janowiak, J., Mo, K., Ropelewski, C., Wang, J., Leetmaa, A., Reynolds, R., Jenne, R., and Joseph, D.: The NCEP/NCAR Reanalysis 40-year project, B. Am. Meteorol. Soc., 77, 437-471, 1996.

Kikuchi, K. and Wang, B.: Spatio-temporal wavelet transform and the multiscale behavior of the Madden-Julian Oscillation. J. Climate, 23, 3814-3834, 2010.

Kiladis, G. N., Wheeler, M. C., Haertel, P. T., Straub, K. H., and Roundy, P. E.: Convectively coupled equatorial waves, Rev. of Geophys., 47, RG3004, doi:10.1029/2008RG000266, 2009.

Kobayashi, H., Matsunaga, T., Hoyano, A., Aoki, M., Komori, D., and Boonyawat S.: Satellite estimation of photosynthetically active radiation in Southeast Asia: Impacts of smoke and cloud cover, J. Geophys. Res., 109, D04102, doi:10.1029/2003JD003807, 2004.

Langmann, B. and Heil, A.: Release and dispersion of vegetation and peat fire emissions in the atmosphere over Indonesia 1997/1998, Atmos. Chem. Phys., 4, 2145-2160, doi:10.5194/acp-4-2145-2004, 2004.

Langner, A. and Siegert, F.: Spatiotemporal fire occurrence in Borneo over a period of 10 years, Global Change Biol., 15, 48-62, doi:10.1111/j.1365-2486.2008.01828.x, 2009.

Latif, M., Anderson, D., Barnett, T., Cane, M., Kleeman, R., Leetmaa, A., O'Brien, J., Rosati, A., and Schneider, E.: A review of the predictability and prediction of ENSO, J. Geophys. Res., 103, 14375-14393, 2008.

Li, W., Luo, C., Wang, D., and Lei, T.: Diurnal variations of precipitation over the South China Sea, Meteorol. Atmos. Phys., 109, 33-46, 2010.

Liebmann, B., Hendon, H. H., and Glick, J. D.: The relationship between tropical cyclones of the western Pacific and Indian Oceans and the Madden-Julian Oscillations, J. Meteor. Soc. Jpn., 73, 401-412, 1994.

Liu, J., Logan, J. A., Jones, D. B. A., Livesey, N. J., Megretskaia, I.,
Carouge, C., and Nedelec, P.: Analysis of CO in the tropical troposphere using Aura satellite data and the GEOS-Chem model: insights into transport characteristics of the GEOS meteorological products, Atmos. Chem. Phys., 10, 12207-12232, doi:10.5194/acp-10-12207-2010, 2010.

Lohmann, U., and Feicher, J.: Global indirect aerosol effects: a review, Atmos. Chem. Phys., 5, 715-735, doi:10.5194/acp-5-7152005, 2005.

Lu, E. and Chan, J. C. L.: A unified monsoonal index for South China, J. Clim., 12, 2375-2385, 1999.

Ludang, Y., Jaya, A., and Inoue, T.: Geohydrological conditions of the developed peatland in Central Kalimantan World Appl. Sci. J., 2, 198-203, 2007.

Madden, R. A. and Julian, P. R.: Detection of a 40-50 Day Oscillation in the Zonal Wind in the Tropical Pacific, J. Atmos. Sci., 28, 702-708, 1971.

Mahmud, M.: Mesoscale model simulation of low level equatorial winds over Borneo during the haze episode of September 1997 J. Earth Syst. Sci., 118, 295-307, 2009a.

Mahmud, M.: Mesoscale equatorial wind prediction in Southeast Asia during a haze episode of 2005, Geofizika, 26, 67-84, 2009b.

Maloney, E. D. and Hartman, D. L.: The Madden Julian oscillation, baratropic dynamics, and the North Pacific tropical cyclone formation, part 1: Observations, J. Atmos. Sci., 58, 2545-2558, 2001.

Masunaga, H. and L'Ecuyer, T. S.: The Southeast pacific warm band and double ITCZ, J. Climate, 23, 1189-1208 2010.

McBride, J. L., Malcolm, R., and Haylock, N. N.: Relationships between the Maritime Continent heat source and the El NiñoSouthern Oscillation phenomenon. J. Climate, 16, 2905-2914, 2003.

Mcfarquahar, G. M. and Wang H.: Effects of aerosols on trade wind cumuli over the Indian Ocean: Model simulations, Q. J. Roy. Meteorol. Soc., 132, 821-843, 2006.

Miettinen, J.: Variability of fire-induced changes in MODIS surface reflectance by land-cover type in Borneo, Int. J. Remote Sens., 28, 4967-4984, 2007.

Miettinen, J. and Liew, S. C.: Connection between fire and land cover change in Southeast Asia: A remote sensing case study in Riau, Sumatra, Int. J. Remote Sens., 26, 1109-1126, 2005.

Miettinen, J. and Liew, S. C.: Burn-scar patterns and their effect on regional burnt-area mapping in insular South-east Asia, Int. J. Wildland Fire, 18, 837-847, doi:10.1071/wf08102, 2009.

Miettinen, J. and Liew, S. C., Degradation and development of peatlands in Peninsular Malaysia and in the islands of Sumatra and Borneo since 1990, Land Degrad. Develop., 21, 285-296, doi:10.1002/ldr.976, 2010.

Miettinen, J., Langner, A., and Siegert, F.: Burnt area estimation for the year 2005 in Borneo using multi-resolution satellite imagery, Int. J. Wildland Fire, 16, 45-53, 2007.

Miettinen, J., Shi C., and Liew, S. C.: Influence of peatland and land cover distribution on fire regimes in insular Southeast Asia, Regional Environ. Change, 11, 191-201, doi:10.1007/s10113-0100131-7, 2010.

Miettinen, J., Shi, C., and Liew, S.- C.: Deforestation rates in insular Southeast Asia between 2000 and 2010, Global Change Biol., 17 2261-2270, doi:10.1111/j.1365-2486.2011.02398.x, 2011.

Miettinen, J., Wong C. M., and Liew S. C.: New 500m spatial resolution land cover map of the western insular Southeast Asia re- 
gion, Intern. J. Remote Sens., 29, 6075-6081, 2008.

Moron, V., Robertson, A. W., and Beer, R.: Spatial coherence and seasonal predictability of monsoon onset over Indonesia, J. Climate, 22, 840-850, 2009.

Neale, R. and Slingo, J.: The Maritime Continent and its role in the global climate: A GCM Study, J. Clim., 16, 834-848, 2003.

Nichol, J.: Smoke haze in Southeast Asia: A predictable recurrence, Atmos. Environ., 32, 2715-2716, 1998.

Page, S. E., Rieley, J. O., and Banks, C. J.: Global and regional importance of the tropical peatland carbon pool, Global Change Biol., 17, 798-818, 2011.

Parameswaran, K., Nair, S. K., and Rajeec, K.: Impact of Indonesian forest fires during the $1997 \mathrm{El}$ Nino on the aerosol distribution over the Indian Ocean, Adv. Space Phys., 33, 1098-1103, 2004.

Peters, M. E., Kuang, Z., and Walker, C.: Analysis of atmospheric energy transport in ERA-40 and implications for simple models of the mean tropical circulation, J. Climate, 21, 5229-5241, 2008.

Rajeev, K., Parameswaran,K., Nair, S. K., and Meenu, S.: Observational evidence for the radiative impact of Indonesian smoke in modulating the sea surface temperature of the equatorial Indian Ocean, J. Geophys. Res., 113, D17201, doi:10.1029/2007JD009611, 2008.

Rasmusson, E. M. and Wallace, J. M.: Meteorological aspects of the El Nino/Southern Oscillation, Science, 16, 1195-1202, doi:10.1126/science.222.4629.1195, 1983.

Reid, J. S., Hobbs, P. V., Rangno, A. L., and Hegg, D. A.: Relationships between cloud droplet effective radius, liquid water content and droplet concentration for warm clouds in Brazil embedded in biomass smoke, J. Geophys. Res., 104, 6145-6153, 1999.

Reid, J. S., Hyer, E. J., Prins, E. M. Westphal, D. L., Zhang, J., Wang, J., Christopher, S. A., Curtis, C. A., Schmidt, C. C., Eleuterio, D. P., Richardson, K. A., and Hoffman, J. P.: Global monitoring and forecasting of biomass-burning smoke: Description and lessons from the Fire Locating and Modeling of Burning Emissions (FLAMBE) program, $\mathbf{J}$ of Sel. Topics in Appl. Earth Obs. and Rem. Sens, 2, 144-162, 2009.

Risk, M. J., Sherwood, O. A., Keikoop, J. M., and Llewellyn, G.: Smoke signals from corals: isotopic signature of the 1997 Indonesian 'haze' event, Marine Geol., 202, 71-78, 2003.

Roundy, P. E.: Analysis of convectively coupled Kelvin waves in the Indian Ocean MJO, J. Atmos. Sci.. 65, 1342-1359, 2008.

Roundy, P. E., Schreck III, C. J., and Janiga, M. A.: Contributions of convectively coupled equatorial Rossby waves and Kelvin waves to the real-time multivariate MJO indeces, Mon. Weather Rev., 137, 469-478, 2009.

Saji, N. H. and Yamagata, T.: Structure of SST and surface wind variability during Indian Ocean Dipole Mode years: COADS observations, J. Climate, 16, 2735-2751, 2003.

Saji, N. H., Goswami, B. N., Vinayachandran, P. N., and Yamagata T.: A dipole mode in the tropical Indian Ocean, Nature, 401, 360-363, 1999.

Sampson, C. R. and Schrader, A. J.: The Automated Tropical Cyclone Forecasting System (Version 3.2), B. Am. Meteorol. Soc., 81, 1231-1240, 2000.

Sapiano, M. R. P. and Arkin, P. A.: An intercomparison and validation of high resolution precipitation estimates with 3-hourly gauge data, J. Hydromet., 10, 149-166, 2009.
Schott, F. A., Xie, S.-P., and McCreary Jr., J. P.: Indian Ocean circulation and climate variability, Rev. Geophys., 47, RG1002, doi:10.1029/2007RG000245, 2009.

Schroeder, W., Csiszar, I., and Morisette, J.: Quantifying the impact of cloud obscuration on remote sensing of active fires in the Brazilian Amazon, Remote Sens. Environ., 112, 456-470, 2008.

Schroeder, W., Prins, E., Giblio, L., Csiszar, I., Schmidt, C., Morisette, J., and Morton, D.: Validation of GOES and MODIS active fire detection products using ASTER and ETM plus data, Remote Sens. Environ, 112, 2711-2726, 2008.

Shen, Y., Xiong, A., Wang, Y., and Xie, P.: Performance of highresolution satellite precipitation products over China, J. Geophys. Res., 115, D02114, doi:10.1029/2009JD012097, 2010.

Shi, J. J., Chang, S. W.-J., and Raman, S.: A numerical study of the outflow layer of tropical cyclones. Mon. Weather Rev., 118, 2042-2055, 1990.

Siegert, F., Ruecker, G., Hinrichs A., and Hoffmann, A. A.: Increased damage from fires in logged forests during droughts caused by El Nino, Nature, 414, 437-440, 2001.

Sow, S. K., Juneng, L., Tangang, F. T., Hussin, A. G., and Mahmud, M.: Numerical simulation of a severe late afternoon thunderstorm over Peninsular Malaysia, Atmos. Res., 99, 248-262, 2011.

Stephens, G. L., Ecuyer, T. L, Forbes, R., Gettlemen, A., Golaz, J. C., Bodas-Salcedo, A., Suzuki, K., Gabriel, P., and Haynes J.: Dreary state of precipitation in global models, J. Geophys. Res., 115, D24211, doi:10.1029/2010JD014532, 2010.

Stolle, F. and Lambin, E. F.: Interprovincial and interannual differences in the causes of land-use fires in Sumatra, Indonesia, Environ. Conserv., 30, 375-387, 2003.

Stolle, F., Chomitz, K. M., Lambin, E. F., and Tomich, T. P.: Land use and vegetation fires in Jambi Province, Sumatra, Indonesia, For. Ecol. Magage., 179, 277-292, 2003.

Streets, D. G., Yarber, K. F., Woo, J. H., and Carmichael G. R.: Biomass burning in Asia: Annual and seasonal estimates and atmospheric emissions, Global Biogeochem. Cy., 17, 1099, doi:10.1029/2003GB002040, 2003.

Sun, Y., Solomon, S., Dai, A. and Portmann, R. W.: How often does it rain?, J. Climate, 19, 916-934, 2007.

Tansey, K., Beston, J., Hoscilo, A., Page, S. E., and Paredes Hernandez, C. U.: Relationship between MODIS fire hot spot count and burned area in a degraded tropical peat swamp forest in Central Kalimantan, Indonesia, J. Geophys. Res., 113, D23112, doi:10.1029/2008JD010717, 2008.

Thampi, B. V., Rajeev, K., Parameswaran, K., and M. K.Mishra M. K.: Spatial distribution of the Southeast Asian smoke plume over the Indian Ocean and its radiative heating in the atmosphere during the major fire event of 2006, Geophys. Res. Lett., 36, L16808, doi:10.1029/2009GL039316, 2009.

Tian, B., Waliser, D. E., Kahn, R. A., Li, Q., Yung, Y. L., Tyranowski, T., Geogdzhayev, I. V., Mishchenko, M. I., Torres, O., and Smirnov, A.: Does the Madden-Julian Oscillation influence aerosol variability?, J. Geophys. Res., 113, D12215, doi:10.1029/2007JD009372, 2008.

Titley, D. W. and Elsberry, R. L.: Large Intensity Changes in Tropical Cyclones: A Case Study of Supertyphoon Flo during TCM90. Mon. Weather Rev., 128, 3556-573, 2000.

Tosca, M. G., Randerson, J. T., Zender, C. S., Flanner, M. G., and Rasch, P. J.: Do biomass burning aerosols intensify drought in 
equatorial Asia during El Nino?, Atmos. Chem. Phys., 10, 35153528, 2010,

http://www.atmos-chem-phys.net/10/3515/2010/.

Tosca, M. G., Randerson, J. T., Zender, C. S., Nelson, D. L., Diner, D. J., and Logan, J. A.: Dynamics of fire plumes and smoke clouds associated with peat and deforestation fires in Indonesia, J. Geophys. Res., 116, D08207, doi:10.1029/2010JD015148, 2011.

Van der Kaars, S., Tapper, N., and Cook, E. J.: Observed relationships between El Nino-Southern Oscillaton, rainfall variability and vegetation and fire history on Halmahera, Maluku, Indonesia, Global Change Biol., 16, 1705-1714, doi:10.1111/j.13652486.2009.02025.x, 2010.

van der Werf, G. R., Randerson, J. T., Collatz, G. J., Giglio, L., Kasibhatla, P. S., Arellano, A. F., Olsen, S. C., and Kasischke, E. S.: Continental-scale partitioning of fire emissions during the 1997 to $2001 \mathrm{El} \mathrm{Nino/La} \mathrm{Nina} \mathrm{period,} \mathrm{Science,} \mathrm{303,} \mathrm{73-76,} 2004$.

van der Werf, G. R., Dempewolf, J., Trigg, S. N., Randerson, J. T., Kasibhatla, P. S., Gigliof, L., Murdiyarso, D., Peters, W., Morton, D. C., Collatz, G. J., Dolman, A. J., and DeFries, R. S.: Climate regulation of fire emissions and deforestation in equatorial Asia, Proc. Natl. Acad. Sci, 104, 20350-20355, 2008.

Van Oldenborgh, G. J., Balmaseda, M. A., Ferranti, L., Stockdale, T. N., and Anderson, D. L. T.: Did the ECMWF Seasonal Forecast Model Outperform Statistical ENSO Forecast Models over the Last 15 Years?, J. Clim., 18, 3240-3249, 2005.

Vayda, A. P.: Causal explanation of Indonesian forest fires: Concepts, applications, and research priorities, Hum. Ecol., 34, 615635, 2006.

Vitart, F., Molteni, F., Simulation of the Madden-Julian Oscillation and its teleconnections in the ECMWF forecast system, Q. J. Roy. Meteorol. Soc., 136, 842-855, 2010.

Wang, B., Huang, F., Wu, Z., Yang, J., Fu, X., and Kikuchi, K.: Multi-scale climate variability of the South China Sea monsoon: A review, Dynam. Atmos. Ocean, 47, 15-37, 2009.

Wang, J., Ge, C., Yang, Z., Hyer, E. J., Reid, J. S., Chey, B.-N., Mahmud, M., Zhang, Y., and Zhang, M.: Mesoscale modeling of smoke transport over the Southeast Asian Maritime Continent: interplay of sea breeze, trade wind, typhoon, and topography, Atmos. Res., submitted, 2012.

Wang, Y., Field, R. D., and Roswintiarti O.: Trends in atmospheric haze induced by peat fires in Sumatra Island, Indonesia and El Ninõ phenomenon from 1973 to 2003, Geophys. Res. Lett., 31, L04103, doi:10.1029/2003GL018853, 2004.

Wheeler, M. and Kiladis, G. N.: Convectively-coupled equatorial waves: Analysis of clouds and temperature in the wavenumberfrequency domain, J. Atmos. Sci., 56, 374-399, 1999.

Wheeler, M. C. and Hendson H. H.: An all-season multivariate MJO index: development of an index for monitoring and prediction, Mon. Weather Rev., 132, 1917-1932, 2004.
Wolff, D. B. and Fisher, B. L.: Assessing the relative performance of microwave-based rainrate retrievals using TRMM ground validation data, J. App. Meteorol. Clim., 48, 1069-1099, 2009.

Wolter, K. and Timlin, M. S.: Measuring the strength of ENSO events - how does 1997/98 rank?, Weather, 53, 315-324, 1998.

Wu, C. H. and Hsu, H. H.: Topographic Influence on the MJO in the Maritime Continent. J. Climate, 22, 5433-5448, 2009.

Wu, P., Hara, M., Hamada, J.-I., Yamanaka, M. D., and Kimura, F.: Why a large amount of rain falls over the sea in the vicinity of western Sumatra island during nighttime, Appl. Meteorol., 48, 1345-1361, doi:10.1175/2009JAMC2052.1, 2009.

Xian, P., Reid, J. S., Turk, J. F., Hyer, E. J., and Westphal, D. L.: Impact of modeled versus satellite measured tropical precipitation on regional smoke optical thickness in an aerosol transport model, Geophys. Res. Lett., 36, L16805, doi:10.1029/2009GL038823, 2009.

Xian, P., Reid, J. S., Atwood, S., Hyer, E. J., Johnson, R. S. and Westphal, D. L.: Smoke transport patterns over the Maritime Continent, Atmos. Res., submitted, 2012.

Yang, S. and Smith, E. M.: Mechanisms for diurnal variability of global tropical rainfall observed from TRMM, J. Clim., 19, 5190-5226, 2006.

Yang, S., Kuo, K.-S, and Smith, E. A.: Persistent nature of secondary diurnal modes of precipitation over oceanic and continental regimes, J. Climate, 21, 4115-4131, doi:10.1175/2008JCLI2140.1, 2008.

Yang, S., Kuo, K.-S., and Smith, E. A.: Persistent Nature of Secondary Diurnal Modes of Precipitation over Oceanic and Continental Regimes. J. Climate, 21, 4115-4131, doi:10.1175/2008JCLI2140.1, 2008.

Yano, J.-I., Blender, R., Zhang, C., and Fraedrich, K.: 1/f noise and pulse-like events in the tropical atmospheric surface variabilities, Q. J. Roy. Meteorol. Soc., 130, 1697-1721, 2004.

Yuan, T., Remer, L. A., Pickering, K. E., and Yu, H.: Observational evidence of aerosol enhancement of lightning activity and convective invigoration, Geophys. Res. Lett., 38, L04701, doi:10.1029/2010GL046052, 2011.

Zhang, C.: The Madden-Julian Oscillation, Rev. Geophys., 43, RG2003, doi:10.1029/2004RG000158, 2005.

Zhang, C. and Dong, M.: Seasonality of the Madden-Julian Oscillation, J. Climate, 17, 3169-3180, 2004.

Zhang, C. and Gottschalck, J.: SST anomalies of ENSO and the Madden-Julian Oscillation in the equatorial Pacific. J. Climate, 15, 2429-2445, 2002.

Zhang, J., Reid, J. S., Westphal, D. L., Baker, N., and Hyer, E. J.: A system for operational aerosol optical depth data assimilation over global oceans, J. Geophys. Res., 113, D10208, doi:10.1029/2007JD009065, 2008. 